\title{
Vaccine distribution chains in low- and middle-income countries: A literature review
}

\author{
Kim De Boeck ${ }^{*}$, Catherine Decouttere and Nico Vandaele \\ Research Centre for Operations Management \\ Department of Decision Sciences and Information Management \\ KU Leuven, Belgium \\ Naamsestraat 69, 3000 Leuven, Belgium
}

kim.deboeck@kuleuven.be; catherine.decouttere@kuleuven.be; nico.vandaele@kuleuven.be

\begin{abstract}
Access to immunization varies greatly across the world. In order to increase vaccine coverage, the required vaccines need to be able to reach the targeted population. However, in low- and middleincome countries, this often turns out to be a challenging task. This article provides a literature review on vaccine distribution chains in low- and middle-income countries and consists of two main parts. The first part elaborates on the characteristics and challenges inherent to such distribution chains. In order to obtain a complete overview, both quantitative and qualitative papers are included. In the second part, relevant operations research and operations management literature is structured according to seven classification criteria: decision level, methodology, part of the vaccine distribution chain modelled, uncertainties and characteristics covered, performance measures, real-life applicability, and countries and vaccines covered. Throughout these classifications, a comparison is made between the issues reported in practice and those investigated in the operations research and operations management literature. Based on this analysis, we identify trends and conclude that several gaps exist, providing a promising avenue for future research.
\end{abstract}

Keywords: healthcare; vaccine distribution chain; low- and middle-income countries; access to immunization; public health; literature review

\section{Introduction}

The importance of proper vaccination can hardly be overstated. Immunization is estimated to prevent two to three million deaths from vaccine-preventable diseases each year (WHO, 2017). However, ten percent of all children worldwide remain unreached by immunization programs in 2016, resulting in an estimate of 19.5 million infants worldwide who did not receive basic vaccines (WHO, 2017; WHO/UNICEF, 2017a). The African region is struggling especially, with a substantial percentage of the unvaccinated children being located in this part of the world (WHO/UNICEF, 2017b).

${ }^{*}$ Corresponding author. 
A necessary requirement for reaching immunization objectives is the availability of the vaccine itself. This in turn is influenced by the way in which the vaccine supply chain is designed and operated (Assi et al., 2013; Brooks, Habimana \& Huckerby, 2017; Lydon et al., 2017; Zaffran et al., 2013). The end-toend vaccine supply chain can be roughly split up in two parts: the manufacturing and the distribution chain subsystems (Figure 1). This literature review focuses on the distribution chain subsystem in lowand middle-income countries (LMICs), which starts with the sourcing of vaccines at the national stock level and ends with the vaccination of the targeted population.

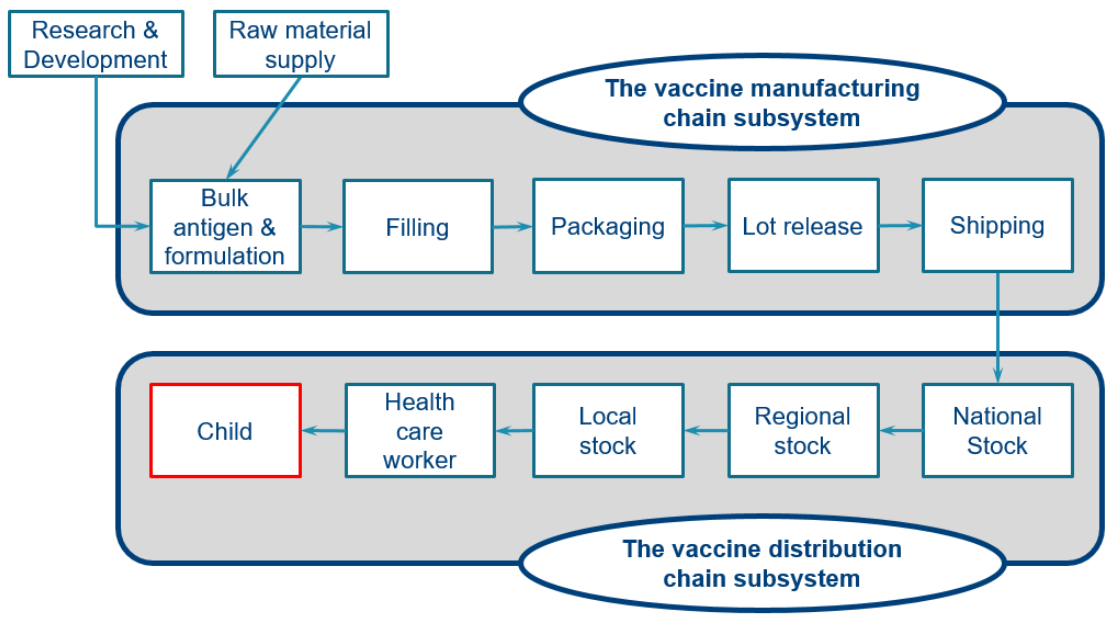

Figure 1: Overview of the end-to-end vaccine supply chain (adapted from Decouttere et al. (2016)).

In this paper, we structure the literature on vaccine distribution chains (VDCs) in LMICs in two ways. First, we provide an overview of the main characteristics and challenges inherent to such distribution chains. In this first part of the review, both quantitative (e.g., optimization papers, cost-effectiveness analyses) and qualitative studies (e.g., case studies, interviews, descriptive papers) are included. Next, in the second part of the review, we focus on the relevant operations research and operations management $(\mathrm{OR} / \mathrm{OM})$ literature and classify these papers according to criteria derived from the first part of the review. This allows us to compare the problems put forward in the broad literature on VDCs in LMICs and those currently addressed in the OR/OM literature, and to identify opportunities for future OR/OM research.

It is important to note the distinction between the WHO-EPI (World Health Organization - Expanded Programme on Immunization) VDC and general pharmacological VDCs in LMICs. The former focuses mainly on childhood vaccines and is the subject of almost all of the work referred to in this paper (although we did not specifically direct our literature search towards this distribution chain). It thus appears that the current literature focusing on VDCs in LMICs mainly looks at the WHO-EPI VDC.

To the best of our knowledge, three literature reviews exist that are related to the topic of this paper. Lemmens, Decouttere, Vandaele and Bernuzzi (2016) review and classify the literature on supply chain network design (SCND) models and investigate whether these existing models can be applied to the vaccine supply chain. They conclude that the currently existing general SCND models are not able to cope with all the typical complexities of a vaccine supply chain. However, their review does not particularly focus on LMICs. Duijzer, van Jaarsveld and Dekker (2018) structure the OR/OM literature on vaccine supply chains into four components: product, production, allocation, and distribution. Similar to Lemmens et al. (2016), they state that vaccine supply chains have several unique characteristics that differentiate from other supply chains. The characteristics outlined in their review are (i) high uncertainty in both supply and demand, (ii) misalignment of objectives and decentralized decision making between suppliers, public health organizations and end customers, (iii) complex 
political decisions concerning allocation, and (vi) the crucial importance of deciding and acting in time. Our literature review differs from Duijzer et al. (2018) since we include both qualitative and quantitative papers, provide a detailed description of the dynamics of VDCs in LMICs, and give an extensive classification of the relevant OR/OM papers along multiple dimensions. Lastly, Songane (2018) gives an overview of the challenges for nationwide vaccine delivery in African countries and what is currently being done to address them. His review mainly focuses on the epidemiological literature and costing analyses, and discusses the role of philanthropic organizations such as the Bill and Melinda Gates Foundation, and global partnerships such as the Global Alliance for Vaccines and Immunization (GAVI) in the development, purchase and delivery of vaccines.

Our contribution to the existing literature is three-fold. First, to the best of our knowledge, this is the first literature review focusing on the specific topic of VDCs in LMICs. Second, both quantitative and qualitative papers are included in our review, which enables us to compare the issues reported in practice to those investigated in the OR/OM literature and to identify gaps between them. Last, we classify the relevant OR/OM literature according to multiple criteria, thereby providing a detailed discussion of the selected papers. In this way, we believe our paper is relevant to both practitioners and OR/OM researchers.

The remainder of this paper is organized as follows. Section 2 explains the search method that led to the selection of articles included in this review. The first part of the literature review is presented in Section 3, and gives an overview of the characteristics (Section 3.1) and challenges (Section 3.2) of VDCs in LMICs. Section 4 contains the second part of the literature review. Based on the overview given in Section 3, classification criteria are derived (Section 4.1) and the relevant OR/OM literature is classified and discussed in detail (Section 4.2). Finally, Section 5 emphasizes the main conclusions and provides directions for further research.

\section{Literature search method}

We searched the databases Web of Science, Scopus, PubMed, and Google Scholar for relevant papers on VDCs in LMICs. An overview of the combinations of keywords used in the initial literature search is given in Table 1. Based on this initial search, an additional search was performed using keywords often encountered in the relevant papers identified during the initial search (Table 1). Furthermore, papers referring to and cited by the obtained set of papers were also added when relevant.

\begin{tabular}{l|l|l}
\hline First keyword & Second keyword & Third keyword \\
\hline Vaccine & Initial search & $(-)$ \\
\cline { 2 - 2 } Immunization & $\begin{array}{l}\text { Distribution supply chain } \\
\text { Supply chain design } \\
\text { Supply chain management } \\
\text { Inventory management } \\
\text { Distribution network } \\
\text { Logistics }\end{array}$ & \\
\cline { 2 - 2 } & Additional search & \\
\cline { 2 - 3 } & Waste & \\
& Demand allocation & \\
& Outreach & \\
Vial size & & \\
\hline
\end{tabular}

Table 1: Overview of combinations of keywords used during the initial and additional literature search. Each search consists of a combination of three keywords (one from each column). "(-)" means that no keyword from that column is used.

To be included in the literature review, papers must be peer-reviewed and written in English. Both quantitative and qualitative studies are included in the first part of the literature review. The second part of the review is restricted to the relevant OR/OM literature. In this paper, a manuscript is 
considered to be OR/OM related if it models and quantitatively analyses (a part of) the VDC. This means that cost-effectiveness analyses, as often encountered in the epidemiological literature, are excluded.

Applying the literature search outlined above, 88 papers are identified and included in this review, of which 37 papers are considered to be OR/OM related. Since the last database search was performed in March 2019, this paper contains articles that were published up until that point in time. Figure 2 shows the distribution of the papers according to the publication year. It is clear that VDCs in LMICs is a recent topic that is getting increased attention, both in general literature as well as in OR/OM research. The peak in 2017 can be explained by the publication of a special issue on immunization supply chains in Vaccine.

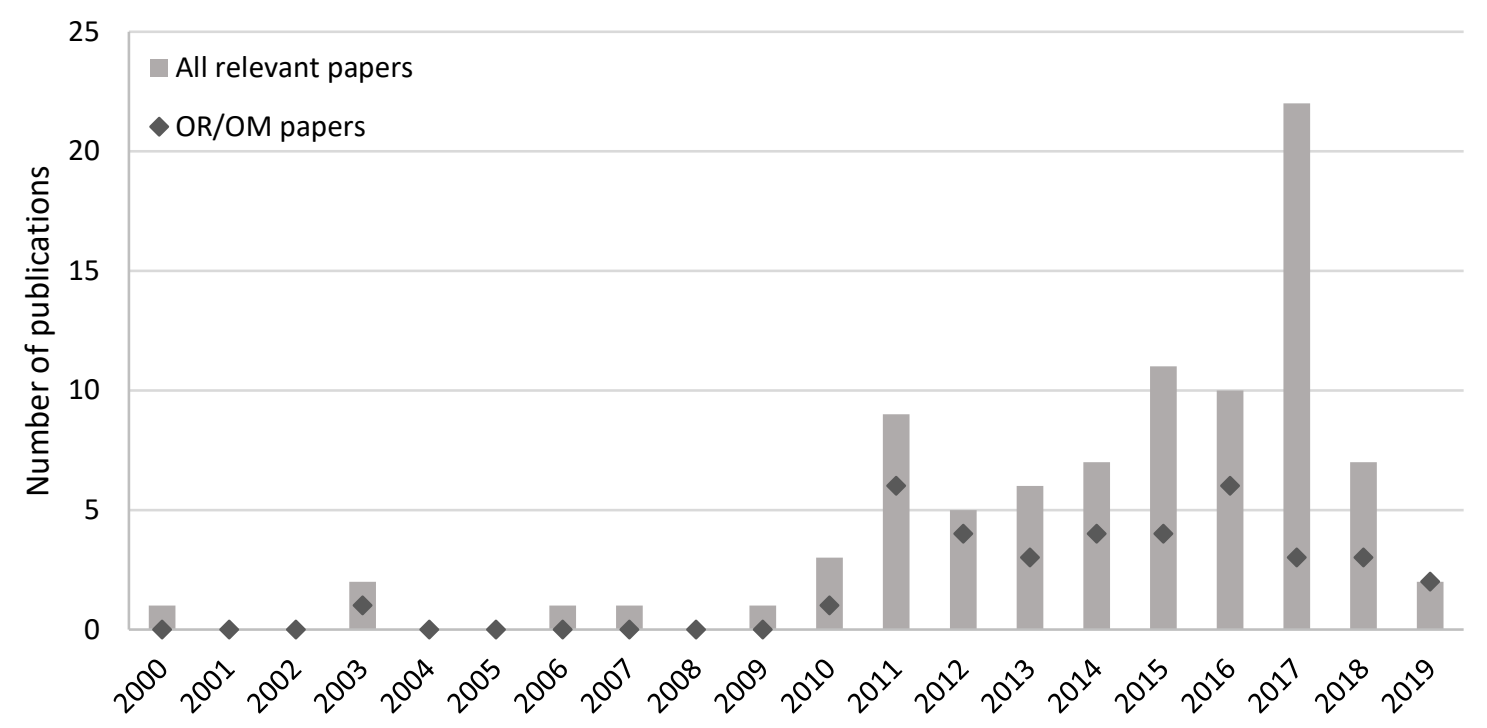

Figure 2: Number of publications by publication year. 2019 includes articles published before the end of March 2019.

\section{Overview of vaccine distribution chains in low-and middle-income countries}

\subsection{Characteristics}

Between the arrival at the national stock and the actual vaccination, vaccines pass through several stages. The structure of VDCs varies between different LMICs with respect to the number of levels (i.e., the number of storage locations the vaccines traverse), the number of storage facilities present at each level, and the location of the push-pull boundary. The number of VDC levels in LMICs typically ranges from three to five, with the majority consisting of four levels: national level, regional level, district level, and health care facility (Lee et al., 2015a). Looking at the number of storage facilities present at each level, a distinction can be made between top-heavy and bottom-heavy VDCs. In order to make this classification, Lee et al. (2015a) calculate an average branching ratio for each level. This branching ratio is defined as the number of storage facilities in the next (i.e., lower) level divided by the number of storage facilities at the current level. A VDC is said to be top-heavy if it has higher branching ratios in the higher levels and bottom-heavy if it has higher branching ratios in the lower levels. The way in which vaccines travel between levels can be either push- or pull-based (Chen et al., 2014; Guillermet, Alfa, Gbodja \& Jaillard, 2017). The point in the VDC where the flow of vaccines switches from push- to pull-based is referred to as the push-pull boundary. When the upper level determines the number of vaccines to be send to the lower level based on an allocation rule, the vaccines are pushed down the VDC (Yadav, 2015). The actual delivery of the vaccines, mostly at fixed time intervals, is then mainly the responsibility of the upper level. Contrarily, in a pull-based system, the lower level calculates the 
required number of vaccines based on local information about consumption and stock status (Yadav, 2015). When vaccines are pulled down the VDC, the lower level mostly picks up the vaccines when needed at the higher level (Karp et al., 2015). Often, vaccines are pushed down through the upper levels and pulled down towards the lower levels (Assi et al., 2011; Chen et al., 2014; Haidari et al., 2015; Lee et al., 2011a; Lee et al., 2012a; Luzze et al., 2017).

We divide the VDC into four main components: sourcing of vaccines at the national level, storage of vaccines at the storage points, transportation of vaccines between levels, and administration of vaccines at the administration points. An overview of these components and their main characteristics is given in the remainder of this section.

\subsubsection{Sourcing}

Appropriate sourcing of vaccines should ideally ensure timely supply of vaccines at the national level, which is the start of the VDC. Unfortunately, insufficient supply to meet demand and national vaccine stock-outs are commonly encountered. When the supply of vaccines is insufficient, allocation rules need to be formulated that decide on the distribution of vaccines to the different storage points (Hirsh Bar Gai, Graybill, Voevodsky \& Shittu, 2018; Lewis et al., 2017). One of the main reasons for national vaccine stock-outs is delays in the procurement process (Lydon et al., 2017; Yadav, 2015). In many cases, LMICs are assisted in the vaccine procurement process by health and humanitarian organizations including the WHO, UNICEF, the Pan American Health Organization (PAHO) and GAVI (Herlin \& Pazirandeh, 2012; Pazirandeh, 2011; Proano, Jacobson \& Zhang, 2012; Woodle, 2000; Yadav, Lydon, Oswald, Dicko \& Zaffran, 2014). These organizations identify a pool of qualified vaccines and manufacturers and make sure that the vaccines are provided at affordable prices. Along with determining the order quantities for each qualified manufacturer, they need to decide on the vaccines' representation (i.e., the physical presentation and composition of the vaccine). In this regard, Proano et al. (2012) formulate an optimization model that identifies the best set of combination vaccines (i.e., vaccines that bundle multiple antigens in one vaccine) to order and their range of feasible prices. Alternatively, national governments of LMICs can also decide to procure the vaccines directly from the manufacturers (Woodle, 2000).

When sourcing vaccines, a decision has to be made whether the vaccines are procured from local or global suppliers. Pazirandeh (2011) proposes a decision making framework for sourcing vaccines within humanitarian aid networks. They point out that although the supply of vaccines is mainly dominated by high-income countries, local sourcing of vaccines provides many advantages including shorter lead times, reduced risks, supporting the development of local markets, and reducing adverse environmental outcomes related to long transportation distances. The main issue related to local sourcing concerns the quality of the vaccines, which is the most important and first criterion assessed in their decision making framework. Thanks to support from non-profit organizations (e.g., UNICEF, GAVI), vaccine production in LMICs has emerged and increased since 2001 (Herlin \& Pazirandeh, 2012; Pazirandeh, 2011).

Even when vaccines have arrived at the port of entry, it can take a significant amount of time before they are shipped to the next level in the VDC. The reason being that vaccine shipments from suppliers may be held in customs for long periods of time (Hirsh Bar Gai et al., 2018). Hence, it is clear that supply at the national level is subject to a lot of uncertainty.

\subsubsection{Storage}

Vaccines have to be stored at cold temperatures, resulting in the need for cold chain equipment at the storage facilities. Ensuring these cold temperatures is a challenging task in LMICs, as cold chain 
equipment is often unreliable due to equipment failures, power outages and an unreliable electricity grid (Azimi, Franzel \& Probst, 2017; Brooks et al., 2017; Hsiao, Desai, Mogasale, Excler \& Digilio, 2017; Karp et al., 2015; Norman et al., 2013). Moreover, preventive maintenance to avoid equipment failures is rarely executed, spare parts are often not available, and repair of cold chain equipment can take months (Ashok, Brison \& LeTallec, 2017; Guillermet et al., 2017; Lennon et al., 2017). As a result, vaccines are exposed to heat or freezing, making part of them unusable and resulting in vaccine wastage or impaired vaccine efficacy (Comes, Bergtora Sandvik \& Van de Walle, 2018; Lemmens et al., 2016; Levin, Levin, Kristensen \& Matthias, 2007; Kristensen, Lorenson, Bartholomew \& Villadiego, 2016).

In an attempt to deal with these problems, several solutions have been investigated. Alternative storage devices instead of traditional electric-powered cold rooms, refrigerators, and freezers are proposed, such as solar-powered refrigerators and passive cold storage devices (PCDs). Whereas solarpowered refrigerators have proven to be highly efficient with low energy consumption, they require properly trained personnel for installation and maintenance (Comes et al., 2018; Chen, Norman, Rajgopal \& Lee, 2015; Mccarney, Robertson, Arnaud, Lorenson \& Lloyd, 2013). PCDs are containers that do not directly rely on an active energy source, but instead keep vaccines cold for extended periods of time using a passive medium such as ice (Chen et al., 2015). One major benefit of PCDs includes less maintenance requirements than refrigerators and freezers (Norman et al., 2013). In addition, PCDs can be easily and rapidly installed at any location (Chen et al., 2015). However, it should be noted that PCDs still indirectly rely on an active energy source since they need to be replenished with ice.

Whereas equipment breakdowns are easy to detect, vaccine heating and freezing due to fluctuating temperatures often go unnoticed. The use of continuous monitoring devices can provide a solution to this problem by detecting and reporting any out-of-range temperature excursions (Ashok et al., 2017; Comes et al., 2018; Lennon et al., 2017). In this way, health care workers have information on the potency of the vaccines and can take actions accordingly. Furthermore, preventive maintenance, triggered by timely indication of temperature fluctuations, can prevent cold chain equipment breakdowns (Lennon et al., 2017). However, this is only possible when the inventory of spare parts is managed properly.

Another solution consists of making vaccines thermostable, thereby partly or completely removing the need for cold chain equipment (Kristensen et al., 2016; Lee et al., 2012b; Levin et al., 2007). As Karp et al. (2015) point out, this could increase vaccine coverage by enabling storage at facilities lacking cold chain equipment and by avoiding administration of vaccines with impaired efficacy induced by heat or freeze exposure. Lee et al. (2017) evaluate thermostable vaccines from an economic point of view and state that several cost and productivity savings can be realized, outweighing substantial price premiums. However, the benefits captured are driven by the duration of vaccine thermostability achieved (Kristensen et al., 2016). Karp et al. (2015) derive three important duration thresholds and the main benefits induced by each of them (Table 2). Also, even making only part of the vaccines thermostable can be of great value, as this relieves cold chain storage and transportation bottlenecks in the VDC (Lee et al., 2012b). 


\begin{tabular}{l|l|l|l}
\hline & Short-term & Mid-term & Long-term \\
\hline Duration threshold & Up to 2 months & Between 2 and 12 months & More than 12 months \\
\hline Main impact & $\begin{array}{l}\text { - Reduced wastage } \\
\text { - Increased vaccine efficacy }\end{array}$ & $\begin{array}{l}\text { - Removal of cold chain } \\
\text { equipment at health posts } \\
\text { - Storage at unequipped } \\
\text { health post }\end{array}$ & $\begin{array}{l}\text { - Removal of cold chain } \\
\text { equipment at all levels } \\
\text { - Possibility of fundamental } \\
\text { re-design of VDC (e.g., } \\
\text { merging with other supply } \\
\text { chains) }\end{array}$ \\
\hline
\end{tabular}

Table 2: Duration thresholds of vaccine thermostability at $40^{\circ} \mathrm{C}$ in a VDC with four levels, and their main impact as defined by Karp et al. (2015).

Adding to the complexity, storage facilities are faced with limited storage capacity that sometimes need to be shared among vaccines and other temperature-sensitive products (e.g., medicines) (Lee et al., 2011a; Lee et al., 2012b). When not properly managed, this might result in vaccine wastage when a delivery of vaccines arrives at the facility and there is no storage space available (Ashok et al., 2017; Kaufmann, Miller \& Cheyne, 2011). The storage requirements can vary significantly between different vaccines and depend heavily on characteristics such as packaging, number of doses per vial, and number of required doses (Chen et al., 2015; Lee et al., 2011b; Lee et al., 2012b; Lee \& Haidari, 2017; Norman et al., 2015). These characteristics are often already decided upon in the R\&D phase (Decouttere, Vandaele, Lemmens \& Bernuzzi, 2016). Norman et al. (2015) conclude that applying a modular packaging system where vial and inner pack dimensions are more consistent between different vaccines increases the packing efficiency of storage devices. Another possible solution that reduces the required storage space is the development of bundled vaccines that combine multiple vaccines in a single injection, such as the measles-mumps-rubella vaccine (Shittu, Harnly, Whitaker \& Miller, 2016).

A main characteristic of vaccines is their limited shelf life, meaning that they have an expiry date after which they cannot be used anymore. Expiry of vaccines is a major form of wastage and needs to be taken into account when managing inventories at the storage facilities (Kaufmann et al., 2011; Kristensen et al., 2016). Depending on the number of levels in the VDC, vaccines spend between 4 and 18 months within the country before administration (Karp et al., 2015). Hence, vaccines need to have remaining shelf lives that are sufficiently long upon arrival at the national stock.

Altogether, this makes the inventory management of vaccines at storage facilities a challenging task. Moreover, these tasks are mostly performed by health care workers having medical backgrounds. This has two important implications (Guillermet et al., 2017). First, the health care workers usually do not receive training on vaccine management, resulting in inefficiencies, unnecessary waste, and stock-outs (Kaufmann et al., 2011; Molemodile, Wotogbe \& Abimbola, 2017; Yadav, 2015). In this regard, Lim, Norman and Rajgopal (2017) propose to use simplified ordering policies based on lean concepts commonly applied in manufacturing settings (e.g., Kanban). Second, it reduces the time that the health care workers can devote to the administration of vaccines (Lee \& Haidari, 2017).

\subsubsection{Transportation}

Transportation of vaccines between levels can be done using a variety of transportation modes. Between higher levels, vaccines are often delivered by means of airplanes, cold trucks and $4 \times 4$ trucks (Assi et al., 2011; Lee et al., 2016; Prosser et al., 2017). At lower levels, the preferred transportation mode mostly depends on the road conditions and the accessibility of the facilities. Reported transportation modes at lower levels include refrigerated and non-refrigerated trucks, public transport, third-party vehicles, motorcycles, bicycles, and carrying vaccines on foot (Comes et al., 2018; Kaufmann et al., 2011; Lee et al., 2012a; Lee et al., 2016; Lim et al., 2017; Mvundura et al., 2015). 
Due to transportation disruptions including bad road conditions (e.g., roads can become inaccessible because of bad weather), possibility of vehicle ransacking, and a variety of vehicle issues, transportation durations are unreliable and remote areas can be very hard to reach (Hsiao et al., 2017; Huang et al., 2017; Lee et al., 2016; Lemmens et al., 2016). This is certainly true for the last mile distribution (Kaucley \& Levy, 2015; Levin et al., 2007). A new mode of transport that is currently being investigated is the use of drones to deliver vaccines (Comes et al., 2018; Haidari et al., 2016; Rabta, Wankmüller \& Reiner, 2018). Although drones do not suffer from many of the road transportation disruptions mentioned above, they bring along other challenges including community perception and acceptance, regulatory issues, and proper maintenance requiring specialized personnel. Since literature focusing on this topic is very limited, Comes et al. (2018) indicate that more research studying the use and impact of drones for VDCs is needed.

During transportation, vaccines need to be kept at specified temperature ranges. This implies the need for adequate cold chain distribution equipment, which is especially challenging for the last mile logistics (Azimi et al., 2017; Lemmens et al., 2016). When refrigerated trucks are not available or not appropriate, vaccine carriers and cool boxes can be used to keep the vaccines cold during transportation. On the one hand, vaccine carriers can be used to transport a small amount of vaccines (typically three litres of vaccines) for a limited time (up to a few hours) (Erdogan, Kannan \& Cheng, 2017). On the other hand, cool boxes have relatively large storage space (twenty to thirty litres of vaccines) and can maintain proper temperatures for up to several days (Chen et al., 2015). Consequently, cool boxes are typically utilized for longer distances, whereas vaccine carriers are mostly used when vaccine distribution is done by public transport, motorcycles, bicycles or on foot (Comes et al., 2018). Particularly for the last mile logistics, making vaccines thermostable could prove to be useful since short thermostability (i.e., up to two months) would already significantly simplify the outreach actions (Karp et al., 2015; Kristensen et al., 2016; Levin et al., 2007; Zipursky et al., 2014).

In an attempt to relieve the VDC, vaccine transportation can be outsourced to third party logistics providers (Molemodile et al., 2017; Riewpaiboon et al., 2015; Sarley et al., 2017; Yadav, 2015). When executed properly, this can result in improved performance and decreased costs of VDCs in comparison to a government-run distribution system (Aina et al., 2017).

Although distribution of vaccines mainly takes place vertically between levels, horizontal distribution between storage facilities within the same level is sometimes used in case of emergencies. That is, when there is a vaccine stock-out, equipment failure or extended power outage, and the upper level is not able to replenish the facility in a timely manner, horizontal replenishment of vaccines can provide a temporary alternative solution (Guillermet et al., 2017).

\subsubsection{Administration}

The final step of the VDC is the actual vaccination. Administration of vaccines can be done at regular immunization sessions, during outreach actions, or throughout immunization campaigns. Regular immunization is done continuously throughout the year at the health care facilities (Karp et al., 2015). However, for some patients, it can be hard to reach these facilities (e.g., they need to travel long distances on foot, or have difficulties paying for transportation) (van den Ent et al., 2017). Consequently, in order to vaccinate patients in remote areas, outreach actions are undertaken by health care workers (Dhamodharan \& Proano, 2012; Kaufmann et al., 2011; Lim, Claypool, Norman \& Rajgopal, 2016). Planning outreach actions includes deciding where and when to conduct an action, as well as which vaccines to administer. Lim et al. (2016) formulate four types of optimization models for selecting the outreach locations that maximize the number of people vaccinated. Additional to regular immunization and outreach sessions, supplementary immunization activities are carried out in the 
form of massive immunization campaigns. These intensive, time-limited and targeted campaigns attempt to vaccinate people who were not reached through regular immunization or outreach actions (Gandhi \& Lydon, 2014; Kaucley \& Levy, 2015). An overview of these three ways of administrating vaccines is given in Figure 3.

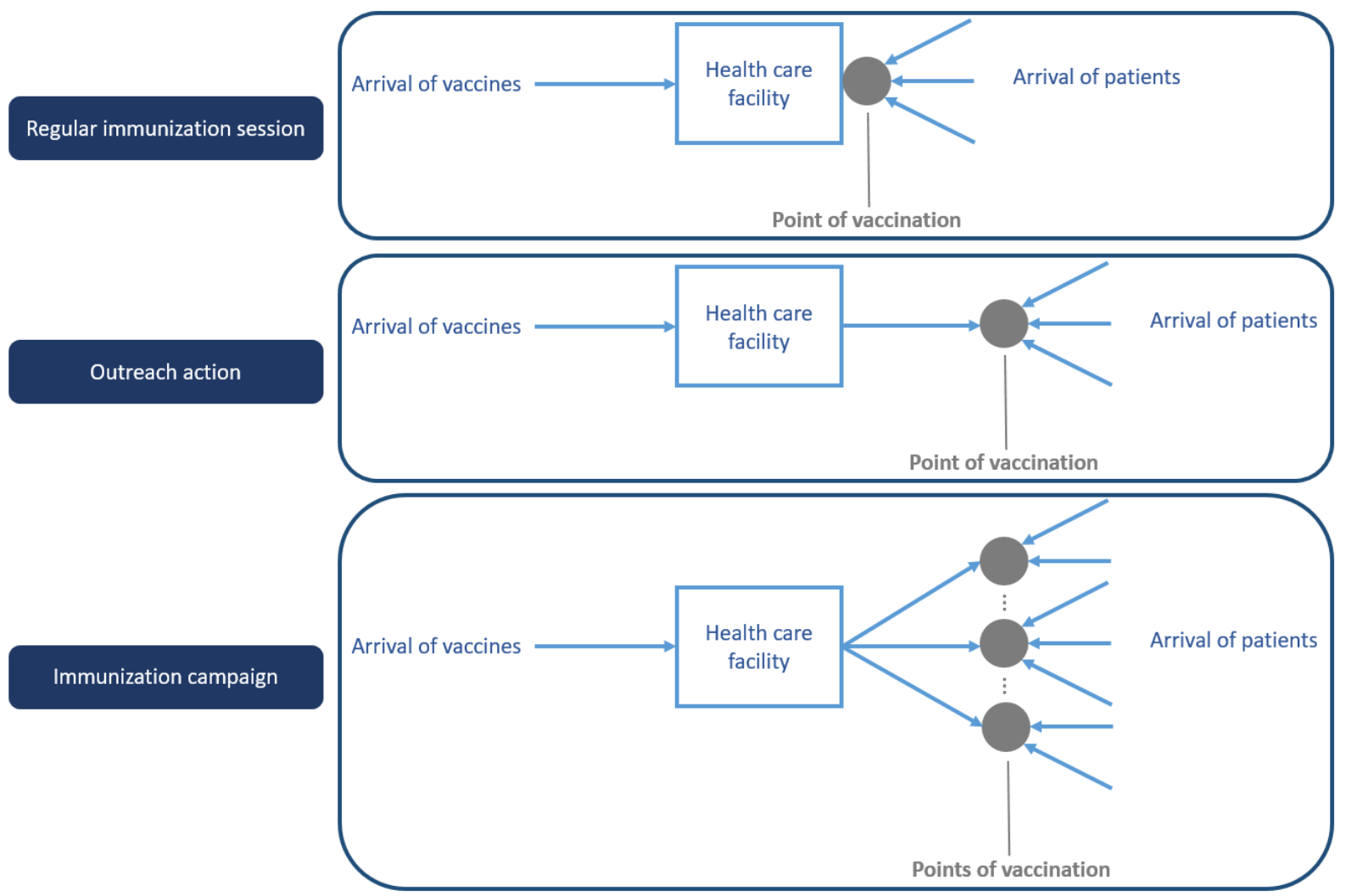

Figure 3: Overview of three ways through which administration of vaccines can be done: regular immunization sessions, outreach actions and immunization campaigns.

Typically, the population density varies between different regions (Lemmens et al., 2016). As such, an allocation decision needs to be made, taking into account equity of vaccine distribution. This is important as geographic locations are a major determinant of immunization inequities. Health care facilities located farther away from intermediate storage points (e.g., in rural areas) typically encounter logistical difficulties in obtaining vaccines, or have only a limited number of qualified health care workers present (Molemodile et al., 2017; van den Ent et al., 2017). Lim et al. (2016) point out that focusing on vaccine coverage might result in an inequitable vaccination plan where remote areas with low population densities are cut off from vaccination. Chen et al. (2014) incorporate equity of vaccine distribution in their model by imposing minimal fractions of demand that must be met for each vaccine at each location.

In order to successfully complete the administration step, several components need to be present at the same time: the patient, the vaccine, the health care worker and any necessary additional material (e.g., syringes, needles, diluents). First of all, the patient needs to show up at the session. The demand for vaccines is often difficult to forecast, as it depends on several factors including seasonality (e.g., bad weather can prohibit patients from travelling to the health care facility), population migration, and community perceptions about vaccine safety (Aina et al., 2017; Ebong \& Levy, 2011; Hsiao et al., 2017; Molemodile et al., 2017). Moreover, for several vaccines, patients need to return multiple times to the health care facility to receive full immunization (Arya \& Prausnitz, 2016; Chen et al., 2014). These required multiple returns often result in high drop-out rates. For example, Bong and Levy (2011) report 
a drop-out rate for BCG-HepB-Hib, which requires three doses for full immunization, of approximately $30 \%$.

Second, the vaccine itself needs to be available. Unfortunately, stock-outs of vaccines at the health care facilities are still commonly encountered (Guillermet et al., 2017; Haidari et al., 2015; Mueller et al., 2016; Prosser et al., 2017). The inability of VDCs to ensure availability of vaccines at the administration points is indicated as a main driver of poor immunization system performance in LMICs (Aina et al., 2017).

Third, a sufficiently skilled health care worker (i.e., a nurse) needs to be present since administration of vaccines mostly occurs through injection (Arya \& Prausnitz, 2016). Since the number of qualified health care workers at a facility is often limited, it might happen that a health care facility needs to close because the qualified health care workers are conducting an outreach action or are collecting vaccines from the upper level (Aina et al., 2017; Sarley et al., 2017; van den Ent et al., 2017). Also, as explained in Section 3.1.2., the health care workers often need to manage vaccine inventories as an additional task, reducing the time they are available to administer vaccines. Alternative administration methods are being investigated that lower the skills needed to administer vaccines and hence increase the pool of eligible vaccinators. Examples are compact, prefilled, auto-disable devices (Drain, Nelson \& Llyod, 2003; Guillermet et al., 2015) and microneedle patches (Arya \& Prausnitz, 2016). Another way consists of avoiding the use of needles, like for example administering oral vaccines (e.g., oral vaccine Polio).

Finally, additional resources might be needed like syringes, needles, or diluents. In some cases, the distribution chains of vaccines and complementary materials are split up since these complementary resources do not always need cold chain distribution (Mvundura et al., 2015). While separating these distribution chains frees up valuable cold chain space, it also increases the risk of missed vaccination opportunities (Guillermet et al., 2015). Altogether, successful vaccination only occurs when all these components (i.e., the patient, the vaccine, the health care worker and any necessary additional material) are present at the same time. This implies the importance of each of them, as absence of a single component immediately results in missed vaccination opportunities.

An important form of wastage encountered in the administration step is open-vial wastage (OVW). This occurs when a multi-dose vial is opened, but not all doses are administered and mainly depends on the vial size and session size (Assi et al., 2011; Mofrad, Maillart, Norman \& Rajgopal, 2014; Mofrad, Garcia, Maillart, Norman \& Rajgopal, 2016). Determining whether to provide a vaccine using single- or multi-dose vials is an important decision as this might have various implications for the VDC. Whereas multi-dose vials require less cold chain space, have lower purchasing costs, and produce less medical waste, they increase contamination risk, inaccurate dosing, and OVW (Assi et al., 2011; Dhamodharan, Proano \& Kumar, 2011; Drain et al., 2003; Haidari et al., 2015; Lee et al., 2011a; Parmar, Baruwa, Zuber \& Kone, 2010; Yang, Parisi, Lahue, Uddin \& Bishai, 2014). The optimal number of doses per vial is highly dependent on the performance measures taken into account and the prioritization of these, often conflicting, performance indicators. This results in the need of a thorough trade-off analysis (Heaton et al., 2017). Also, the number of doses per vial in a multi-dose vial can vary (e.g., a 10-dose vial can contain 8,9 or 10 doses) due to clinician variation, syringe type, and spoilage (Dhamodharan \& Proano, 2012; Guichard et al., 2010; Lee et al., 2010; Mofrad et al., 2014; Mofrad et al., 2016; Wallace et al., 2017). Although this is pointed out by numerous papers, only one paper in this literature review (i.e., Mofrad et al., 2016) takes this characteristic into account by introducing random vial yield and vial failures in their model. Ideally, the number of doses in a vial should be tailored to the session size and vaccine type. However, this can turn out to be difficult to implement in practice as it complicates inventory management and ordering policies (Assi et al., 2011). 
Generally, policy dictates that when a multi-dose vial is depleted, a new vial should be opened upon the arrival of a patient. However, following this administration policy of never turning away a patient results in high OVW rates and frequent stock-outs (Mofrad et al., 2014; Mofrad et al., 2016). Moreover, anecdotal evidence is found of health care workers turning away patients for vaccination when this would result in wasting most of the doses in the vial (Drain et al., 2003; Haidari et al., 2015; Heaton et al., 2017; Lee et al., 2010; Wallace et al., 2017). Consequently, administration policies are looked into to determine vial opening thresholds above which it is worthwhile to open an additional multi-dose vial (e.g., Haidari et al., 2015; Mofrad et al., 2014; Mofrad et al., 2016; Mofrad, Maillart, Norman \& Rajgopal, 2018).

Lastly, administration of vaccines often produces waste that needs to be disposed (Lee et al., 2011a). Improper disposal of injection waste can have severe medical consequences (Assi et al., 2011; Haidari et al., 2015). Special care needs to be taken by the health care workers to make sure that needles are not reused, both intentionally as well as accidently (Arya \& Prausnitz, 2016). Therefore, safety boxes can be utilized during vaccination sessions in order to safely store the used syringes (Hutton \& Tediosi, 2006). After the vaccination session is completed, the collected waste is transported in the safety boxes to the disposal site. Methods of sharps-disposal used in LMICs include incineration and applying a "burn and bury method" (Hutton \& Tediosi, 2006; Mvundura et al., 2015). The latter means that the safety boxes are thrown into deep holes, fired, and buried. Zaffran et al. (2013) indicate an opportunity to reduce the environmental impact of waste disposal by implementing safe and environmentally friendly sharps-disposal methods, and reusing and recycling non-sharps waste and packaging materials.

\subsection{Challenges}

3.2.1. Related to the operation of vaccine distribution chains in low- and middle-income countries

\subsubsection{Limited resources}

VDCs in LMICs have very limited health care resources including transportation and storage capacity, and health care staff (Chen et al., 2014; Lee et al., 2016). As a result, most VDCs are currently strained, and will not be able to cope with the new vaccine introductions that are planned in the coming years (Huang et al., 2017; Lee et al., 2011b; Lee et al., 2015a; Lee et al., 2016; Shittu et al., 2016).

Hence, investments in additional health care capacity are needed (Brooks et al., 2017; Mvundura et al., 2015). Confronted with a limited budget, the decision in which type of capacity to invest is not always straightforward. First, before making any investment, it is important to determine which type of capacity constitutes the bottleneck (Assi et al., 2011). Adding storage capacity when transportation capacity is severely strained might result in poor outcomes (i.e., have no effect on vaccine availability or even result in decreasing coverage rates) (Haidari et al., 2013; Mueller et al., 2016). Moreover, when investing in a certain type of capacity, multiple ways of doing so may exist. For example, an investment in transportation capacity can either be done by buying more vehicles or by increasing the frequency of delivery (Haidari et al., 2013; Mueller et al., 2016). Likewise, health care work forces can be strengthened by adding more logistics staff or by providing extra training to existing health care personnel. Second, one has to decide at which points in the VDC this capacity will be added, thereby taking into account the equity of vaccine distribution (Chen et al., 2014).

In order to make best use of limited resources, VDCs need to operate as efficiently as possible (Ebong \& Levy, 2011). A proposed solution in the literature to increase efficiency is to integrate the VDC with other health commodity distribution chains such as maternal and child health medicines, and family planning (Songane, 2018; Wallace, Dietz \& Cairns, 2009; Yadav et al., 2014). Particularly for reaching 
remote areas, sharing logistics can decrease incurred costs to a great extent (Lloyd \& Cheyne, 2017). However, this also introduces additional challenges including capacity allocation between vaccines and other health products (Luzze et al., 2017). Yadav et al. (2014) and Wallace et al. (2009) both conclude in their literature review that although many papers exist that elaborate on the possible benefits and risks of integrating VDCs with other health commodity distribution chains in LMICs, quantitative research on this topic is lacking. Indeed, to the best of our knowledge, OR/OM research addressing this question is still non-existent (see also Section 4.2.1).

\subsubsection{Vaccine wastage}

VDCs are faced with high percentages of vaccine wastage (Guichard et al., 2010; Mofrad et al., 2014; Parmar et al., 2010; Wallace et al., 2017). There are two main types of wastage: closed- and open-vial wastage. First, closed-vial wastage (CVW) is mostly a consequence of the uncertainties and characteristics inherent to a VDC including unreliable transportation and storage equipment, and limited shelf life. Examples of CVW are vaccines that cannot be used anymore because of varying temperatures, and vaccines broken or lost during transportation or storage (Assi et al., 2013; Azimi et al., 2017; Chen et al., 2014; Wallace et al., 2017; Yang et al., 2014). Another important contributor to CVW is failure to return unopened vials to the health care facility after an outreach session (Guichard et al., 2010). Second, as explained in section 3.1.4, OVW occurs when a multi-dose vial is opened, but not all doses are administered. Especially outreach actions are faced with high percentages of OVW (Dhamodharan \& Proano, 2012). The amount of OVW at an immunization session mainly depends on the vial size and the session size (Guichard et al., 2010; Lee at al., 2010; Yang et al., 2014). The session size is further determined by the catchment area size, the number of vaccination days per month, and the vaccine type (Mofrad et al., 2014). Correct estimation of OVW is important since it is taken into account when deciding on vaccine ordering quantities and thus can influence the occurrence of stockouts (Chen et al., 2015; Ebong \& Levy, 2011; Lim et al., 2017; Rajgopal et al., 2011; Wallace et al., 2017). Hence, reducing waste in the future is imperative as the costs of vaccines and the need for storage capacity are already high and will further increase in the future (Mofrad et al., 2016; Shittu et al., 2016; Songane, 2018). Moreover, the fact that demand already exceeds supply (Erdogan et al., 2017) further underscores the importance of avoiding vaccine wastage.

When managing inventories, it is important to consider the trade-off between wastage and stock-outs. Whereas overstocking leads to CVW because of the expiration of inventories, understocking might result in stock-outs and thus missed vaccination opportunities (Guichard et al., 2010; Rajgopal et al., 2011; Zaffran et al., 2013). This trade-off becomes more pronounced as the re-supply intervals are longer (Yadav, 2015). The WHO recommends adding a buffer of $25 \%$ to the predicted demand when determining vaccine inventory levels (Assi et al., 2011; Lim et al., 2017; Rajgopal et al., 2011).

\subsubsection{Future outlook}

VDCs need to be able to absorb shocks caused by unexpected health emergencies such as epidemic outbreaks, the occurrence of armed conflicts, and natural disasters (Brooks et al., 2017; Decouttere et al., 2016). With storage and transportation capacity already pushed to their limits, strategies to get vaccines to the targeted population in a timely manner during health emergencies should be set out. Consequently, there is a need for adaptable, responsive, and resilient VDCs.

Assi et al. (2013) suggest that reducing the number of levels in a VDC can shorten the time needed to distribute vaccines from the national stock to the health care facilities during emergency situations. Another option that enables fast emergency response is the construction of vaccine stockpiles (Gandhi et al., 2013; Hsiao et al., 2017; Kaufmann et al., 2011). This brings along several challenging decisions (Duijzer et al., 2018). First, one has to determine where to locate the vaccine stockpiles and how many 
vaccines to keep in stock. Second, when an emergency situation occurs, an allocation decision has to be made since the vaccine stockpiles mostly do not carry enough inventory to vaccinate all the eligible patients. Surprisingly, to the best of our knowledge, there are no studies that quantitatively address these decisions in LMICs (see also Section 4.2.1).

Also, VDCs need to be able to cope with changes in the vaccination schedules, mostly coming from new vaccine introductions, and the resulting increased capacity requirements (Brown et al., 2014; Guillermet et al., 2017; Zaffran et al., 2013). Often, newly introduced vaccines are bulkier than the vaccines currently present in the VDC. For example, the recently introduced Rotavirus vaccine is especially large compared to the current EPI vaccines (Chen et al., 2015). Lee et al. (2012a) show that the introduction of new vaccines can overwhelm the VDC, resulting in decreased overall vaccine availability.

\subsubsection{Related to research on vaccine distribution chains in low- and middle-income countries}

\subsubsection{Data availability}

In order to analyse VDCs in LMICs and make well-informed investment and operational decisions, reallife data is needed. However, required data is often not available or not reliable as many countries still depend on paper-based data collection systems, imposing few quality standards (Brooks et al., 2017; Prosser et al., 2017). Mvundura et al. (2015) state that only a few LMICs collect system costs for their VDC and hence collect their own data by means of interviews and field visits. Also, Karp et al. (2015) indicate a lack of data on the cold chain equipment performance in LMICs, which led to decision making based on anecdotal information. Guichard et al. (2010) report that between $30 \%$ and $38 \%$ of the records could not be used in their data analysis on vaccine wastage in Bangladesh because of the poor data quality. Further, Shittu et al. (2016) explain that since accurate information about vaccine demand is not available, static forecasting tools based on proxies such as birth rates are often used. However, these methods might underestimate demand because of unregistered births or unknown populations in difficult-to-reach areas. Also, when parts of the country's population migrate, these methods result in a mismatch between the predicted and the realized demand, thereby wasting valuable resources (Mueller et al., 2016). Moreover, as the census data is mostly only updated every few years, estimates are based on outdated assumptions, and incorrect vaccine demand forecasts are repeated year after year (Kaufmann et al., 2011; Yadav, 2015).

A possible solution is the adoption of well-managed information systems. Although a range of information management systems have been developed for LMICs, it is often unclear how to manage the data or maintain the computer program (Brooks et al., 2017). Consequently, these expensive information systems cannot result in increased data availability. In an attempt to tackle this issue, GAVI is working on data standardization across countries and appropriate information systems (Brooks et al., 2017).

When reliable data is available, this can be used as input data for research and can also facilitate the management of VDCs. A well-managed, integrated information system can assist inventory managers by providing them with data on actual stock levels (Lee et al., 2012a; Riewpaiboon et al., 2015; Sarley et al., 2017). In addition, it can enable the use of accurate demand forecasting systems (Mueller et al., 2016). Visualization of data can further simplify vaccine inventory management, provide increased transparency regarding vaccine stock-outs and improve vaccine allocation (e.g., by showing the stock levels of all storage facilities on dashboards) (Molemodile et al., 2017; Ottih, Cussen \& Mustafa, 2018; Shittu et al., 2016). 
It should be noted that while data availability and reliability are important issues that need to be addressed with better data capture, it should not be an impediment to developing models. Indeed, even approximate estimates will provide better guidance than the current ad hoc decisions that are made without any analytical rigor.

\subsubsection{Implementation}

Too often, there is no connection to the stakeholders and tools and models are developed without taking into account the countries or logisticians that need to use them (Brooks et al., 2017). Moreover, putting results from scientific research into action often turns out to be a complex exercise (Lee et al., 2015b). As a consequence, implementation in practice is limited (Decouttere et al., 2016).

In order to tackle this issue, Decouttere et al. (2016) propose a five-step framework for designing a vaccine supply chain system that aggregates stakeholders' perspectives and mathematical modelling. In the first step, the different stakeholders are mapped together with the goals and limitations of the vaccine supply chain. Examples of relevant stakeholders in VDCs are health and humanitarian organizations (e.g., GAVI, UNICEF, WHO), national governments, patients, and health care workers. Based on the outcome of this map, the key performance measures and design requirements are determined in the second step. This is done by applying a combination of qualitative research methods including brainstorms, interviews, observations, and workshops. The third step explicitly formulates and models the relevant designs and scenarios, which need to be validated by the relevant stakeholders. Next, in the fourth step, the design and scenarios are ranked based on the key performance measures defined in the second step. Lastly, a final design is decided upon in the fifth step in collaboration with the stakeholders.

Lee et al. (2015b) and Lee et al. (2016) also emphasize that by engaging in-country stakeholders, more accurate and complete models and scenarios can be developed. They point out that although an abundant number of possible scenarios might exist with regard to scientific research, often only a few are relevant in practice (Lee et al., 2015b). Molemodile et al. (2017) further emphasize the importance of including stakeholders at the end points of the VDC (e.g., health care workers, patients) as it is at this last mile that the actual vaccinations are realized. Finally, the national governments should be included as political will and commitment are often key to a successful implementation of research (Aina et al., 2017).

\section{Classification of the OR/OM literature}

\subsection{Classification criteria}

Based on the overview of VDCs in LMICs given in Section 3, we classify the relevant OR/OM literature according to seven classification criteria: decision level, methodology, part of the VDC modelled, uncertainties and characteristics covered, performance measures, real-life applicability, and countries and vaccines covered.

Decision level. The literature can be classified into three decision levels: strategic, tactical, and operational (Schmidt \& Wilhelm, 2000). First, strategic decisions have a long-term impact and cannot be changed on short notice after implementation. This includes facility location and allocation decisions, and defining vaccine representations. Second, tactical decisions are made within the boundaries set by the strategical level and have mid-term implications. Examples are deciding on transportation modes and shipping policies, determining inventory levels, and setting transportation and storage capacities. Last, the operational decision level involves short-term, daily supply chain operations such as administration policies, demand forecasting, and inventory policies. 
Methodology. We categorize according to three types of methodology: calculation method, analytical optimization, and simulation. When applying a calculation method, the analysis is purely based on deterministic, simple calculations. Hence, this method is not able to define optimal solutions, but rather focuses on comparisons between a fixed number of scenarios. On the contrary, analytical optimization methods are characterized by their ability to return an optimal solution for the problem under consideration. Finally, a paper is considered to apply simulation if it incorporates uncertainty in the analysis by simulating at least one stochastic input parameter.

Part of the VDC modelled. As explained in Section 3, the VDC can be divided into four main components: sourcing of vaccines at the national level, storage of vaccines at the storage points, transportation of vaccines between levels, and administration of vaccines at administration points. Hence, for each of the selected OR/OM papers, we indicate which part(s) of the VDC they model.

Uncertainties and characteristics covered. VDCs are subject to an abundant number of uncertainties and have very specific characteristics. To compare the issues reported in the literature as outlined in Section 3 to those considered in the OR/OM literature, we classify selected papers according to the uncertainties and characteristics covered. To maintain a structured overview, we group them per VDC component. The following uncertainties and characteristics are used to classify the selected papers:

- Sourcing: stochastic supply of vaccines at the national level.

- Storage: limited storage capacity, unreliable storage equipment, limited vaccine shelf life, CVW during storage.

- Transportation: Limited transportation capacity, multiple transportation modes, stochastic transportation times, CVW during transportation.

- Administration: Stochastic demand, OVW, multiple patient returns, assembly of multiple components (i.e., the patient, the vaccine, the health care worker, and any necessary additional material), stochastic number of doses in a vial, outreach sessions and immunization campaigns, equity of vaccine distribution.

Performance measures. Following Vandaele and Decouttere (2013), we consider three types of performance measures: economic, technological, and value. First, the economic dimension is related to costs and profits. Next, technological performance measures focus on resources and material flow through the supply chain. Finally, the value dimension refers to health, societal, ethical, and environmental values.

Real-life applicability. We study three degrees of applicability. The first one is the use of real-life data. This can be done by obtaining data through public or private databases, or by collecting data through field studies, interviews and observations. The second degree is stakeholder involvement. Stakeholder involvement is considered to be present if the authors validated the proposed models, scenarios or outcomes at least once with one of the stakeholders. The final degree is implementation or further use of the results after the research. This can be identified by qualitative papers reporting on case studies and pilot studies that were carried out following an OR/OM study. Also, the OR/OM papers that indicate the stakeholders' intention to implement the research into practice are classified as having incorporated this third degree of real-life applicability.

Countries and vaccines covered. Lastly, to provide insights on possibly interesting case studies in the future, we distinguish articles based on the countries and vaccines covered in the analysis. 


\subsection{Classification results}

Although many papers emphasize the need to improve VDCs in LMICs, the number of OR/OM publications addressing this issue by modelling and quantitatively analysing (part of) the VDC is not overwhelming; 37 OR/OM papers focus on this research topic.

It is important to note that out of these 37 selected papers, 15 papers can be clustered as HERMES models. HERMES (Highly Extensible Resource for Modelling Event-Driven Supply Chains) is a discreteevent simulation model that represents the flow of vaccines from the manufacturer to the patient (Assi et al., 2011; Lee et al., 2011a). Since these papers are based on the same model, they can be considered as a cluster, and we indicate this throughout the classifications.

Table 3 gives an overview of the journals in which the selected papers are published. Relevant OR/OM papers are found in OR/OM journals as well as in epidemiological and medical journals. The articles published in Vaccine represent a substantial percentage of the relevant epidemiological and medical literature. On the contrary, manuscripts from OR/OM journals are scattered over the different journals and none of the OR/OM journals has published more than two selected articles. Moreover, all the HERMES papers are published in epidemiological and medical journals. A possible explanation might be that much of the OR/OM work in the area of VDCs in LMICs calls for solutions that can be applied easily along with novel models, and not necessarily novel methodology. The focus of OR/OM journals on theory and methodology might therefore explain why articles are scattered across just a few OR/OM journals.

\begin{tabular}{l|l}
\hline Journal & Frequency \\
\hline Vaccine & 17 (11 HERMES) \\
Annals of Operations Research & 2 \\
IIE Transactions & 2 \\
IIE Annual Conference Proceedings & 2 \\
Operations Research for Health Care & 2 \\
PLoS ONE & 2 (2 HERMES) \\
American Journal of Public Health & 1 (1 HERMES) \\
BMC Public Health & 1 (1 HERMES) \\
Engineering Management Journal & 1 \\
Health affairs & 1 \\
Health Care Management Science & 1 \\
International Journal of Health Care Finance and Economics & 1 \\
International Journal of Disaster Risk Reduction & 1 \\
Omega & 1 \\
OR Spectrum & 1 \\
Socio-Economic Planning Sciences & 1 \\
Total & 37 \\
\hline \multicolumn{2}{c}{ Table 3: Classification of selected papers according to journal. }
\end{tabular}

\subsubsection{Decision level}

Strategic decision level. As is clear from Table 4, a high number of the selected papers concentrate on the strategic decision level. A frequently observed research topic within this level is defining the vaccines' representation. Particularly the effects of varying vaccine vial sizes have received a lot of attention (e.g., Assi et al., 2011; Dhamodharan et al., 2011; Dhamodharan \& Proano, 2012; Haidari et al., 2015; Lee et al., 2010; Lee et al., 2011a; Wedlock et al., 2019; Yang et al., 2014). A main conclusion of these manuscripts is that an overall optimal vaccine vial size does not exist. On the one hand, Haidari et al. (2015) find that it depends on the vaccine characteristics, the organization of the VDC, the immunization session size, and the goals of the stakeholders. Dhamodharan et al. (2011), on the other 
hand, define arrival rates and purchase cost functions as the most important factors affecting optimal vaccine vial sizes. Research addressing other aspects of vaccines' representation is more scarce. Only two articles focus on this; Proano et al. (2012) and Norman et al. (2015) look into bundling of vaccines and vaccine packaging, respectively.

Another stream of manuscripts within the strategic decision level concentrates on the (re-)design of the VDC network. Assi et al. (2013), Brown et al. (2014), Lee et al. (2015a), Lee et al. (2016) and Shittu et al. (2016) explore the impact of simplifying the VDC by removing or consolidating VDC levels and report on a variety of positive effects induced by these simplifications. Erdogan et al. (2017) formulate a model to find the optimal locations of regional distribution centres within the African continent and the optimal allocation of countries to these centres. Hirsh Bar Gai et al. (2018) also analyse location and allocation decisions of distribution centres, but focus on VDC network design within a country rather than between countries (as is done in Erdogan et al. (2017)). Likewise, Chen et al. (2014) formulate a model to solve allocation decisions between storage points within a country. Applying location-allocation models on a more detailed level, Lim et al. (2016) present four coverage models to select outreach locations in order to maximize the number of residents that can be reached.

Other strategic decisions addressed in the relevant literature are the use of PCDs (Chen et al., 2015; Norman et al., 2015) and the impact of making vaccines thermostable (Lee et al., 2012b; Lee et al., 2017).

\begin{tabular}{l|l}
\hline Decision level & References \\
\hline Strategic & Chen et al. (2014); Chen et al. (2015); Dhamodharan et al. (2011); Dhamodharan and Proano (2012); \\
& Erdogan et al. (2017); Hirsh Bar Gai et al. (2018); Lee et al. (2010); Lim et al. (2016); Norman et al. \\
& (2013); Norman et al. (2015); Proano et al. (2012); Shittu et al. (2016); Yang et al. (2014); \\
& HERMES [Assi et al. (2011); Assi et al. (2013); Brown et al. (2014); Haidari et al. (2015); Lee et al. \\
& (2011a); Lee et al. (2011b); Lee et al. (2012a); Lee et al. (2012b); Lee et al. (2015a); Lee et al. (2016); \\
& Lee et al. (2017); Wedlock et al. (2019)]. \\
\hline Tactical & $\begin{array}{l}\text { Chen et al. (2014); Erdogan et al. (2017); Hirsh Bar Gai et al. (2018); Rabta et al. (2018); Rottkemper } \\
\text { et al. (2011); Shittu et al. (2016); }\end{array}$ \\
& $\begin{array}{l}\text { HERMES [Assi et al. (2013); Brown et al. (2014); Haidari et al. (2013); Haidari et al. (2016); Lee et al. } \\
\text { (2011b); Lee et al. (2012a); Lee et al. (2015a); Lee et al. (2016); Mueller et al. (2016)]. }\end{array}$ \\
\hline Operational & $\begin{array}{l}\text { Azadi et al. (2019); Dervaux et al. (2003); Dhamodharan et al. (2011); Dhamodharan and Proano } \\
\text { (2012); Lim et al. (2017); Mofrad et al. (2014); Mofrad et al. (2016); Mofrad et al. (2018); Rajgopal et } \\
\end{array}$ \\
& al. (2011); \\
& HERMES [Haidari et al. (2015); Mueller et al. (2016)].
\end{tabular}

Tactical decision level. Papers studying tactical decisions mostly concentrate on storage and transportation capacities. On the one hand, Hirsh Bar Gai et al. (2018) determine the storage capacities needed to achieve a $100 \%$ fill rate at the storage locations in the VDC. Also Shittu et al. (2016) look into storage requirements; they explore the effects of variance in supply and demand on the storage capacity needed. On the other hand, focusing on transportation, Assi et al. (2013) and Brown et al. (2014) analyse the impact of altering shipping policies and frequencies. Finally, Haidari et al. (2013) and Mueller et al. (2016) take into account both storage and transportation limitations by comparing the impact of multiple combinations of increasing storage capacity, transportation capacity and transportation frequency at different levels in the VDC. Note that none of the articles focus on the third limited health care resource indicated in Section 3, namely the health care staff.

A few manuscripts focus on the transportation modes to deliver vaccines. Erdogan et al. (2017) determine the transportation modes to be used to transfer vaccines between distribution centres located in different countries. They consider three main transportation options in their model: airplane, car, and several types of cold trucks. Exploring a new way of shipping, Haidari et al. (2016) assess the impact of operating drones for routine vaccine distribution. They find that applying drones 
could be beneficial if they are used frequently enough to overcome the capital costs of installation and maintenance. Rabta et al. (2018) point out that drones are particularly useful to overcome last-mile distribution problems during emergency situations (i.e., inaccessibility to cut-off regions). They present an optimization model for the delivery of multiple packages of light-weight relief items (e.g., vaccines) via drones to a certain number of remote locations within a disaster prone area.

One article addresses relocation of inventory during emergency situations. Rottkemper et al. (2011) develop a model for inventory relocation between storage points in an overlapping disaster setting. They consider an immunization campaign that aims at confining the spread of an epidemic. During this campaign, disruptions in demand and/or supply can occur. During such a disruption, the storage point can be served either from another storage point at the same level or from a storage point at the upper level. Although this situation is looked at from a disaster relief perspective, it has some similarities with the trade-off between vertical (i.e., standard) and horizontal (i.e., emergency) vaccine deliveries as explained in Section 3.1.3.

Operational decision level. At the operational decision level, about half of the selected articles study vaccine administration policies. The need for these policies arises from the high values of OVW for multi-dose vials reported in practice. In this regard, Mofrad et al. (2014) formulate a model in which the decision is made whether or not to open an additional multi-dose vial as a function of the time of day, the current vial inventory, and the remaining clinic days until the next replenishment. Using this model, they determine thresholds on the vaccination clinic operating hours and session frequency. Several extensions of this model are presented in Mofrad et al. (2016) and Mofrad et al. (2018). Similarly, Dervaux, Leleu, Valdmanis and Walker (2003) model the optimal number of administration hours and sessions in order to maximize the number and type of vaccines provided, taking into account OVW. Azadi, Gangammanavar and Eksioglu (2019) also optimize vial-opening decisions. However, they state that these decisions are interrelated with ordering decisions and hence consider both of them together in their optimization model. Additional to an optimal administration policy, Mofrad et al. (2014), Mofrad et al. (2016), Mofrad et al. (2018) and Azadi et al. (2019) look into heuristic administration policies and conclude that these policies perform very well compared to the optimal ones. Lastly, Haidari et al. (2015) analyse the impact of administration policies on the optimal vaccine vial sizes.

Another frequently researched topic at the operational decision level includes ordering policies. Whereas Azadi et al. (2019) simultaneously address ordering and administration decisions in their optimization model, the other articles focus on the former one. First, Dhamodharan et al. (2011) and Dhamodharan and Proano (2012) propose a modified periodic review policy that determines the optimal vial size and reorder point for a given vaccine. Second, Rajgopal et al. (2011) develop a spreadsheet model to investigate the effect of different ordering policies combined with various buffer stock levels. Finally, Lim et al. (2017) propose alternative ordering policies based on lean concepts commonly applied in manufacturing settings (e.g., Kanban) in order to simplify and improve the vaccine inventory management system.

Although the unpredictable nature of demand and the practice of bad forecasting methods are highlighted in literature (see Section 3), only two OR/OM papers address this issue. On the one hand, Mueller et al. (2016) introduce a demand forecasting system to adjust vaccine ordering during various degrees of population movement. On the other hand, Rajgopal et al. (2011) compare basing orders on the arrival rates seen in previous sessions and on long-term historical averages. They indicate that the method of determining the patient arrival rate influences the ability of a clinic to maximize the demand that is met. 
Discussion. To conclude, we find that research on VDCs in LMICs tends to focus on the strategic decision level and to a lesser extent on the tactical and operational level. When comparing the issues highlighted in Section 3 to the problems addressed in the OR/OM articles, several gaps can be identified. Indeed, we observe that a variety of problems receives little attention or even remains unexplored in the current OR/OM literature. Moreover, this is true for all three decision levels, despite the fact that more articles focus on strategic decisions. For example, at the strategic decision level, to the best of our knowledge, no OR/OM research exists that looks into outsourcing part of the VDC or integrating VDCs with other health care products. In addition, the question how to prepare for and react to unexpected health emergencies occurring in VDCs in LMICs (e.g., the creation and allocation of vaccine stockpiles) remains unanswered. Although research exists that considers these problems on an international level or in high-income countries (Duijzer et al., 2018), to the best of our knowledge, no OR/OM research in this field focuses on LMICs. Next, a tactical decision not present in the current $\mathrm{OR} / \mathrm{OM}$ literature is the allocation of health care staff; future research could investigate the number of health care workers needed and the optimal allocation of these health care workers to health centres within a district. Also, the trade-off between vertical (i.e., standard) and horizontal (i.e., emergency) vaccine deliveries and the optimal allocation of vaccines to the different available transportation modes received little attention. Lastly, research topics at the operational decision level not covered by published OR/OM manuscripts include maintenance decisions and spare part inventory management applied to VDCs in LMICs, and the determination of appropriate buffers at various points in the VDC (compared to the $25 \%$ buffer that the WHO recommends). Also, demand forecasting is only addressed to a limited extent.

\subsubsection{Methodology}

Calculation method. The number of articles applying a calculation method is very limited; only two articles are classified according to this methodology (Table 5). Lim et al. (2017) and Norman et al. (2015) rely on deterministic calculations to compare different packaging schemes and ordering policies, respectively. The limited occurrence of this methodology in the selected articles can be explained by the fact that a calculation method does not allow to account for any variability. However, as outlined in Section 3, VDCs are subject to a high number of uncertainties and it is thus not surprising to see that most manuscripts opt to use a more sophisticated methodology.

\begin{tabular}{|c|c|}
\hline Methodology & References \\
\hline Calculation method & Lim et al. (2017); Norman et al. (2015). \\
\hline Analytical optimization & $\begin{array}{l}\text { Azadi et al. (2019); Chen et al. (2014); Dervaux et al. (2003); Dhamodharan et al. (2011); } \\
\text { Dhamodharan and Proano (2012); Erdogan et al. (2017); Hirsh Bar Gai et al. (2018); Lim et al. } \\
\text { (2016); Mofrad et al. (2014); Mofrad et al. (2016); Mofrad et al. (2018); Proano et al. (2012); } \\
\text { Rabta et al. (2018); Rottkemper et al. (2011); } \\
\text { HERMES [Lee et al. (2015a)]. }\end{array}$ \\
\hline Simulation & $\begin{array}{l}\text { Azadi et al. (2019); Chen et al. (2015); Dhamodharan and Proano (2012); Hirsh Bar Gai et al. } \\
\text { (2018); Lee et al. (2010); Lim et al. (2017); Mofrad et al. (2016); Mofrad et al. (2018); Norman } \\
\text { et al. (2013); Rajgopal et al. (2011); Shittu et al. (2016); Yang et al. (2014); } \\
\text { HERMES [Assi et al. (2011); Assi et al. (2013); Brown et al. (2014); Haidari et al. (2013); Haidari } \\
\text { et al. (2015); Haidari et al. (2016); Lee et al. (2011a); Lee et al. (2011b); Lee et al. (2012a); Lee } \\
\text { et al. (2012b); Lee et al. (2015a); Lee et al. (2016); Lee et al. (2017); Mueller et al. (2016); } \\
\text { Wedlock et al. (2019)]. }\end{array}$ \\
\hline
\end{tabular}

Table 5: Classification according to methodology.

Analytical optimization. When the goal of the research consists of finding an optimal solution for the problem at hand, relevant articles tend to apply analytical optimization in their analysis. A first stream of papers using this methodology are those addressing strategic location and allocation decisions, and tactical inventory relocation decisions. In these papers, reported optimization methods include linear programming (Chen et al., 2014), binary integer programming (Hirsh Bar Gai et al., 2018; Lee et al., 
2015a; Lim et al., 2016) and mixed integer programming (Erdogan et al., 2017; Rottkemper et al., 2011). A second stream of articles focuses on the operational decision level. On the one hand, Dhamodharan et al. (2011) and Dhamodharan and Proano (2012) utilize non-linear programming and binary integer programming, respectively, to find optimal ordering policies. On the other hand, analytical optimization is also used in current literature to analyse administration policies. First, Markov processes are applied in Mofrad et al. (2014), Mofrad et al. (2016) and Mofrad et al. (2018) who formulate the decision whether or not to open a multi-dose vaccine vial as a Markov decision process. Second, evaluating best practices, Dervaux et al. (2003) perform data envelopment analysis (DEA) to investigate the optimal number of administration hours and sessions. Last, Azadi et al. (2019) present a two-stage stochastic mixed integer non-linear programming model to simultaneously solve vial-opening and ordering decisions.

When using analytical optimization, an important trade-off exists between the complexity of the model and the feasibility of the resulting formulation. Indeed, while adding complexity makes the model more realistic, it also makes it more difficult to solve, and hence additional solution methods might need to be incorporated. For example, Azadi et al. (2019) use Gomory mixed integer and mixed integer rounding cuts to address the non-convexity of the first-stage problem in their model (i.e., the ordering decision problem).

Simulation. The most commonly used methodology in our paper sample is simulation. It is either used as a tool to validate and test the solutions found by analytical optimization (e.g., Azadi et al., 2019; Mofrad et al., 2018) or for the main analysis. In the latter case, it can be combined with analytical optimization (e.g., Dhamodharan and Proano (2012) integrate a Monte Carlo simulation with binary integer programming to find an optimal ordering policy) or applied as a stand-alone methodology. When solely relying on simulation, articles mostly perform a scenario-based analysis. The HERMES models compare and report on a variety of scenarios including adopting different vial sizes (e.g., Assi et al., 2011; Haidari et al., 2015; Lee et al., 2011a; Wedlock et al., 2019), removing and consolidating levels in the VDC network (e.g., Assi et al., 2013; Brown et al., 2014; Lee et al., 2016), and adding various amounts of storage and transportation capacity (e.g., Haidari et al., 2013; Mueller et al., 2016). Additionally, Chen et al. (2015) and Norman et al. (2013) investigate scenarios that introduce different possible PCD designs.

A main advantage of simulation is the ability to include a high level of complexity and it can therefore capture a system's real-life behaviour more easily than analytical optimization methods. However, a major drawback is that scenario-based simulation models are often case-specific, which makes it difficult to derive general conclusions. Indeed, the selected articles applying simulation mostly model particular cases and are thus only able to report findings applied to the specific situations under study.

Discussion. Depending on the problem under consideration, different methodologies might be opted for. Given the inability of calculation methods to incorporate stochastic processes in the analysis, only two articles apply this methodology. The choice between analytical optimization and simulation mostly depends on the approach taken to investigate the problem on hand. While manuscripts seeking an optimal solution opt to apply analytical optimization, articles concentrating on scenario-based analysis tend to go for simulation. This implies that simulation-optimization has not yet been applied to the setting of VDCs in LMICs which opens up opportunities for future research.

\subsubsection{Part of VDC modelled}

It is clear from Table 6 that although a lot of the classified articles model multiple parts of the VDC, only the HERMES models cover the whole VDC from sourcing at the national stock level until the vaccination of the patient. Among the other articles, 9 incorporate three parts in their model, 7 include 
two components and 6 solely focus on one part of the VDC. Articles taking into account three components, mostly omit the first step of the VDC (i.e., sourcing of vaccines) and hence focus on storage, transportation, and administration of vaccines. Only Erdogan et al. (2017) do not consider the administration of vaccines, but instead concentrate on sourcing, storage, and transportation. When modelling two parts of the VDC, a frequently observed combination consists of incorporating storage and administration (Azadi et al., 2019; Mofrad et al., 2014; Mofrad et al., 2016; Mofrad et al., 2018; Shittu et al., 2016). There are only two exceptions; Lim et al. (2016) and Norman et al. (2015) model transportation together with vaccine administration and storage, respectively. Articles that narrow down their focus even more and only consider one VDC component mainly look into the administration of vaccines (Dervaux et al., 2003; Lee et al., 2010; Rajgopal et al., 2011; Yang et al., 2014). Alternatively, Rabta et al. (2018) solely include transportation, while Proano et al. (2012) exclusively study the sourcing component.

Another finding from Table 6 is that, while storage, transportation, and administration of vaccines are widely covered by the classified papers, very few model the beginning of the VDC (i.e., sourcing of vaccines at the national stock level). A possible explanation for this might be that most of the articles' focus lies further down the VDC and hence they consider the sourcing decision as given.

Discussion. The number of parts of the VDC taken into account in the analysis varies greatly among the selected articles. Whereas only the HERMES models cover the whole VDC and hence include all four components, the number of manuscripts including three, two and one component, respectively, are more or less equal. Within each group of papers modelling the same number of VDC components, a clear trend is observed as articles within the same group tend to consider the same parts of the VDC.

\begin{tabular}{|c|c|c|c|c|}
\hline \multirow[t]{2}{*}{ References } & \multicolumn{4}{|c|}{ Part of VDC modelled } \\
\hline & Sourcing & Storage & Transportation & Administration \\
\hline Azadi et al. (2019) & & $\mathrm{X}$ & & $\mathrm{X}$ \\
\hline Chen et al. (2014) & & $x$ & $x$ & $x$ \\
\hline Chen et al. (2015) & & $x$ & $x$ & $x$ \\
\hline Dervaux et al. (2003) & & & & $x$ \\
\hline Dhamodharan et al. (2011) & & $x$ & $x$ & $x$ \\
\hline Dhamodharan and Proano (2012) & & $x$ & $x$ & $x$ \\
\hline Erdogan et al. (2017) & $x$ & $x$ & $x$ & \\
\hline Hirsh Bar Gai et al. (2018) & & $x$ & $x$ & $x$ \\
\hline Lee et al. (2010) & & & & $x$ \\
\hline Lim et al. (2016) & & & $x$ & $x$ \\
\hline Lim et al. (2017) & & $x$ & $x$ & $x$ \\
\hline Mofrad et al. (2014) & & $x$ & & $x$ \\
\hline Mofrad et al. (2016) & & $x$ & & $x$ \\
\hline Mofrad et al. (2018) & & $x$ & & $x$ \\
\hline Norman et al. (2013) & & $x$ & $x$ & $x$ \\
\hline Norman et al. (2015) & & $x$ & $x$ & \\
\hline Proano et al. (2012) & $x$ & & & \\
\hline Rabta et al. (2018) & & & $x$ & \\
\hline Rajgopal et al. (2011) & & & & $\mathrm{x}$ \\
\hline Rottkemper et al. (2011) & & $x$ & $x$ & $x$ \\
\hline Shittu et al. (2016) & & $x$ & & $x$ \\
\hline Yang et al. (2014) & & & & $x$ \\
\hline $\begin{array}{l}\text { HERMES [Assi et al. (2011); Assi et al. (2013); } \\
\text { Brown et al. (2014); Haidari et al. (2013); }\end{array}$ & $x$ & $x$ & $x$ & $x$ \\
\hline Haidari et al. (2015); Haidari et al. (2016); Lee & & & & \\
\hline et al. (2011a); Lee et al. (2011b); Lee et al. & & & & \\
\hline (2012a); Lee et al. (2012b); Lee et al. (2015a); & & & & \\
\hline $\begin{array}{l}\text { Lee et al. (2016); Lee et al. (2017); Mueller et } \\
\text { al. (2016); Wedlock et al. (2019)] }\end{array}$ & & & & \\
\hline
\end{tabular}




\subsubsection{Uncertainties and characteristics covered}

Sourcing. A main finding of Section 4.2.3 is that very few articles explicitly consider the first step of the VDC. Looking into detail at these articles, Table 7 shows an even more striking observation; no single article models stochastic supply of vaccines at the national stock level. On the one hand, Proano et al. (2012) focus on the number of vaccines to purchase per vaccine type from manufacturers and assume that the manufacturers are able to supply the requested number of vaccines. On the other hand, Erdogan et al. (2017) and the HERMES papers look further down the VDC and also consider transporting vaccines from the national stock level to lower levels. On top of the assumption that manufacturers can produce the required number of vaccines, they also assume that delivery of vaccines at the national level occurs deterministically at fixed time intervals. However, as pointed out in Section 3.1.1, national stock-outs and insufficient supply to meet demand are commonly encountered in LMICs. In addition, upon arrival at the national stock level, vaccines may be held in customs for long periods of time before being shipped to the next level in the VDC. Altogether, this results in rather stochastic national supply of vaccines.

Storage. Comparing the uncertainties and characteristics related to the storage of vaccines as outlined in Section 3.1.2 to the ones taken into account by the selected OR/OM articles (Table 7), two main findings can be noted. First, a majority of the manuscripts incorporate limited cold chain storage space into their model. This limited storage space is often not only reserved for vaccines, but is also used to store additional material. Chen et al. (2014), Lim et al. (2017), Norman et al. (2013) and the HERMES papers take into consideration that, besides vaccines, diluents must also be stored in refrigerators before they are used. Furthermore, Chen et al. (2015) and Norman et al. (2013) account for the fact that PCDs need ice to maintain the required cold temperatures and thus less space is left to store vaccines.

A second major finding from Table 7 is that, besides limited storage space, other uncertainties and characteristics inherent to storage of vaccines are either not accounted for in the analysis or are only modelled sporadically. On the one hand, very few articles explicitly model vaccines' limited shelf life and CVW. Erdogan et al. (2017) consider vaccines' expiration duration based on cold-chain life to determine whether vaccines need to be shipped by air or ground transportation. Next, the HERMES papers include both limited shelf life and CVW in their analysis. In the HERMES simulation model, each vaccine vial has a specified life time beyond which its doses expire. In addition, they define storage CVW as inventory losses from broken vials or temperature exposure, and model these by adopting an inventory loss rate (expressed by a fixed percentage). Similarly, Chen et al. (2014) represent CVW in their analysis by defining a fraction of vaccines that is lost in storage due to breakage and pilferage. Lastly, Rottkemper et al. (2011) model CVW caused by rebels who break into a storage point and destroy all vaccines stored at the storage location. On the other hand, none of the manuscripts consider unreliable storage equipment. This is in contrast to Section 3.1.2 where papers report frequent occurrence of equipment failures in combination with a lack of preventive maintenance and the unavailability of spare parts. 


\begin{tabular}{|c|c|c|c|c|}
\hline \multirow[t]{2}{*}{ References } & \multicolumn{4}{|c|}{ Uncertainties and characteristics covered } \\
\hline & Sourcing & Storage & Transportation & Administration \\
\hline Azadi et al. (2019) & N.A. & & N.A. & Stochastic demand, OVW, outreach. \\
\hline Chen et al. (2014) & N.A. & Limited capacity, CVW. & $\begin{array}{l}\text { Limited capacity, different } \\
\text { transportation modes, CVW. }\end{array}$ & OVW, equity of vaccine distribution. \\
\hline Chen et al. (2015) & N.A. & Limited capacity. & $\begin{array}{l}\text { Limited capacity, different } \\
\text { transportation modes. }\end{array}$ & Stochastic demand, OVW. \\
\hline Dervaux et al. (2003) & N.A. & N.A. & N.A. & ovw. \\
\hline Dhamodharan et al. (2011) & N.A. & & & Stochastic demand, OVW, outreach. \\
\hline Dhamodharan and Proano (2012) & N.A. & & & Stochastic demand, OVW, outreach. \\
\hline Erdogan et al. (2017) & & Limited capacity, limited shelf life. & $\begin{array}{l}\text { Limited capacity, different } \\
\text { transportation modes. }\end{array}$ & N.A. \\
\hline Hirsh Bar Gai et al. (2018) & N.A. & Limited capacity. & & Stochastic demand. \\
\hline Lee et al. (2010) & N.A. & N.A. & N.A. & Stochastic demand, OVW. \\
\hline Lim et al. (2016) & N.A. & N.A. & & Outreach. \\
\hline Lim et al. (2017) & N.A. & Limited capacity. & Limited capacity. & Stochastic demand, OVW. \\
\hline Mofrad et al. (2014) & N.A. & Limited capacity. & N.A. & Stochastic demand, OVW. \\
\hline Mofrad et al. (2016) & N.A. & Limited capacity. & N.A. & $\begin{array}{l}\text { Stochastic demand, OVW, stochastic } \\
\text { number of doses in a vial. }\end{array}$ \\
\hline Mofrad et al. (2018) & N.A. & Limited capacity. & N.A. & Stochastic demand, OVW. \\
\hline Norman et al. (2013) & N.A. & Limited capacity. & Limited capacity. & Stochastic demand, OVW. \\
\hline Norman et al. (2015) & N.A. & Limited capacity. & Limited capacity. & ovw. \\
\hline Proano et al. (2012) & & N.A. & N.A. & N.A. \\
\hline Rabta et al. (2018) & N.A. & N.A. & Limited capacity. & N.A. \\
\hline Rajgopal et al. (2011) & N.A. & N.A. & N.A. & Stochastic demand, OVW. \\
\hline Rottkemper et al. (2011) & N.A. & Limited capacity, CVW. & $\begin{array}{l}\text { Limited capacity, different } \\
\text { transportation modes. }\end{array}$ & $\begin{array}{l}\text { Stochastic demand, immunization } \\
\text { campaigns, equity of vaccine } \\
\text { distribution. }\end{array}$ \\
\hline Shittu et al. (2016) & N.A. & Limited capacity. & N.A. & Stochastic demand. \\
\hline Yang et al. (2014) & N.A. & N.A. & N.A. & Stochastic demand, OVW. \\
\hline $\begin{array}{l}\text { HERMES [Assi et al. (2011); Assi et al. (2013); Brown et } \\
\text { al. (2014); Haidari et al. (2013); Haidari et al. (2015); } \\
\text { Haidari et al. (2016); Lee et al. (2011a); Lee et al. } \\
\text { (2011b); Lee et al. (2012a); Lee et al. (2012b); Lee et al. } \\
\text { (2015a); Lee et al. (2016); Lee et al. (2017); Mueller et } \\
\text { al. (2016)] }\end{array}$ & & $\begin{array}{l}\text { Limited capacity, limited shelf life, } \\
\text { CVW. }\end{array}$ & $\begin{array}{l}\text { Limited capacity, different } \\
\text { transportation modes, CVW. }\end{array}$ & Stochastic demand, OVW. \\
\hline HERMES[Wedlock et al. (2019)] & & $\begin{array}{l}\text { Limited capacity, limited shelf life, } \\
\text { CVW. }\end{array}$ & $\begin{array}{l}\text { Limited capacity, different } \\
\text { transportation modes, CVW. }\end{array}$ & Stochastic demand, OVW, outreach. \\
\hline
\end{tabular}

Table 7: Classification according to uncertainties and characteristics covered. "N.A." means that the paper does not consider the selected VDC component. 
Transportation. Similar to papers that consider vaccine storage, most papers that include transportation of vaccines model limited transportation capacity. Additionally, quite some articles account for different transportation modes. However, it should be noted that both the type of transportation mode and the number of vaccines shipped by each mode are mostly determined upfront. Hence, the different transportation modes are considered as a parameter of the model and not a variable that needs to be optimized or decided on. One exception is the article of Erdogan et al. (2017) where the usage of several transportation modes is determined by the model in order to optimize the delivery of vaccines to selected countries in Africa.

Also here, several uncertainties and characteristics elaborated on in Section 3.1.3 are not accounted for or are only considered to a limited extent by the OR/OM community. First, only a small number of papers model CVW during transportation. More specifically, the articles that do so are roughly the same articles that account for CVW during storage (i.e., Chen et al., 2014; HERMES papers). Hence, CVW during transportation is modelled in a similar way as during storage; a fixed percentage of the vaccines is assumed to be lost during transportation because of breakage, pilferage, or temperature exposure. Second, no single paper models stochastic transportation times. Indeed, all articles including transportation of vaccines estimate the duration of transportation between two storage locations by an average value and do not account for any uncertainty with respect to this value. This is a somewhat surprising observation since VDCs in LMICs are characterized by a variety of transportation disruptions including bad road conditions (e.g., roads can become inaccessible because of bad weather), possibility of vehicle ransacking, and a variety of vehicle issues. This is certainly true for the last mile; remote areas can be very hard to reach. Consequently, transportation durations in LMICs are highly unreliable and thus stochastic in nature.

Administration. A large majority of the manuscripts modelling the administration of vaccines account for stochastic demand. These papers can be further classified according to the arrival distribution and time-variability in arrival rates. On the one hand, vaccine demand is mostly assumed to follow a Poisson distribution (e.g., Chen et al., 2015; Dhamodharan et al., 2011; Dhamodharan \& Proano, 2012; Lee et al., 2010; Lim et al., 2017; Norman et al., 2013; Rajgopal et al., 2011; HERMES papers). Additionally, Lee et al. (2010) also investigate scenarios that use a Uniform arrival distribution in order to represent different patterns of clinic-level demand. They conclude that the main insights of their study are identical for Uniform and Poisson arrival distributions. On the contrary, Hirsh Bar Gai et al. (2018) and Shittu et al. (2016) assume that the vaccine demand arrival follows a Lognormal distribution, while Mofrad et al. (2014), Mofrad et al. (2016) and Mofrad et al. (2018) approximate the demand by a Bernoulli distribution. In addition, Mofrad et al. (2018) also consider Binomial distributed demand. Lastly, two articles fit a distribution to real-life data; Azadi et al. (2019) find that the demand arrival fits a Negative Binomial distribution, while depending on the considered case study, Yang et al. (2014) state that the demand is either Negative binomial, Poisson, Uniform, or Geometric distributed. Using an alternative way of modelling stochastic demand, Rottkemper et al. (2011) consider different probabilities of additional demand. On the other hand, only one manuscript includes time-variability in the arrival rate. That is, all papers except for Mofrad et al. (2018) assume stationary demand arrivals. However, Mofrad et al. (2018) state that there is plenty of anecdotal evidence that the arrivals are non-stationary; they report on the occurrence of morning-overcrowding at health care facilities and note that there tends to be higher demand on Mondays and Fridays. Therefore, their model incorporates non-stationary arrival rates throughout the replenishment cycle as well as within each session.

Likewise, almost all articles consider OVW. However, the way in which they do so varies. On the one hand, OVW is observed as an outcome of the model (e.g., Azadi et al., 2019; Lee et al., 2010; Mofrad 
et al., 2016; Mofrad et al., 2018; Rajgopal et al., 2011; Yang et al., 2014; HERMES papers). That is, when the number of doses in a vial and the realized demand are known, the OVW during an immunization session can be determined exactly. On the other hand, OVW is used as an input into the model. This can be done in two ways: by estimating OVW through a proxy, and by using real-life data. Adopting the first method, Chen et al. (2014), Lim et al. (2017), Norman et al. (2013) and Norman et al. (2015) assume in their model that a fraction of vaccine vials is lost due to OVW. They then use this percentage to inflate demand in order to estimate the inventory actually consumed. Chen et al. (2015) and Dhamodharan and Proano (2012) obtain OVW estimates through simulation. Alternately, Dhamodharan et al. (2011), Mofrad et al. (2014), Mofrad et al. (2016) and Mofrad et al. (2018) derive an analytical expression to approximate average OVW. Opting for the second method, Dervaux et al. (2003) use real-life data reported in literature as an input into their DEA analysis.

Although stochastic demand and OVW are included by most manuscripts that consider the administration of vaccines, there still exist several gaps between the uncertainties and characteristics indicated in Section 3.1.4, and those considered by the relevant OR/OM manuscripts. First, only five articles consider outreach sessions (i.e., Azadi et al., 2019; Dhamodharan et al., 2011; Dhamodharan \& Proano, 2012; Lim et al., 2016; Wedlock et al., 2019). Moreover, only one of them looks at the combination of regular immunization sessions and outreach actions (i.e., Wedlock et al., 2019). Nevertheless, a connection exists between these two types of immunization sessions. For example, they are often performed by the same health care workers, implying that when an outreach action is being conducted, staffing levels at the health care facility to perform regular immunization drop. Furthermore, only one article focuses on immunization campaigns in LMICs (i.e., Rottkemper et al., 2011) and no OR/OM papers exist that combine the three ways of administering vaccines (i.e., regular vaccination sessions, outreach actions, immunization campaigns) into one study. Second, only two papers consider equity of vaccine distribution (i.e., Chen et al., 2014; Rottkemper et al., 2011). Third, Mofrad et al. (2018) are the only paper that accounts for variability in the number of doses that can be drawn from a multi-dose vial. Last, we observe from Table 7 that no OR/OM research exists that investigates the requirement of multiple components to be present at the same time in order to generate a successful vaccination (i.e., the patient, the vaccine, the health care worker, any necessary additional material). Likewise, none of the studies from Table 7 explicitly model the necessity of multiple patient returns in order to receive full immunization for certain vaccines and the effect of drop-out rates between these required returns.

Discussion. We conclude that the number of modelled uncertainties and characteristics inherent to VDCs in LMICs is rather limited in the OR/OM community. Hence, an important gap exists between the uncertainties and characteristics outlined in the broad literature on VDCs, and those addressed by the OR/OM literature. To the best of our knowledge, no OR/OM articles exist that model stochastic national supply of vaccines, unreliable storage equipment, stochastic transportation times, requirement of multiple components at the vaccine administration step, or requirement of multiple patient returns. Moreover, limited shelf life, CVW during storage and transportation, outreach actions and immunization campaigns, stochastic number of doses in a multi-dose vial, and equity of vaccine distribution are only addressed to a limited extent by the OR/OM community. As a result, a variety of research opportunities arises by including and/or investigating some of these uncertainties and characteristics.

\subsubsection{Performance measures}

As can be derived from Table 8 , approximately $70 \%, 40 \%$ and $75 \%$ of the classified articles include economic, technological and value performance measures, respectively, in their study (these percentages add up to more than $100 \%$ as multiple papers include more than one type of performance 
measure). This means that the value dimension is taken into account most. Since the topic of VDCs in LMICs is located in the field of health and humanitarian operations, this is a laudable observation. Moreover, these percentages also imply that economic performance measures are widely considered in the relevant OR/OM papers. On the contrary, the technological dimension is not often consulted compared to the other two dimensions.

\begin{tabular}{|c|c|c|c|}
\hline \multirow[t]{2}{*}{ References } & \multicolumn{3}{|c|}{ Performance measures } \\
\hline & Economic & Technological & Value \\
\hline Azadi et al. (2019) & $\mathrm{x}$ & & $\mathrm{X}$ \\
\hline Chen et al. (2014) & $x$ & & $x$ \\
\hline Chen et al. (2015) & $x$ & & \\
\hline Dervaux et al. (2003) & & & $x$ \\
\hline Dhamodharan et al. (2011) & $x$ & & \\
\hline Dhamodharan and Proano (2012) & $x$ & & \\
\hline Erdogan et al. (2017) & $x$ & & \\
\hline Hirsh Bar Gai et al. (2018) & $x$ & $x$ & \\
\hline Lee et al. (2010) & $x$ & & $x$ \\
\hline Lim et al. (2016) & & & $x$ \\
\hline Lim et al. (2017) & $x$ & $x$ & \\
\hline Mofrad et al. (2014) & & & $x$ \\
\hline Mofrad et al. (2016) & $x$ & & $x$ \\
\hline Mofrad et al. (2018) & & & $x$ \\
\hline Norman et al. (2013) & $x$ & & \\
\hline Norman et al. (2015) & & $x$ & $x$ \\
\hline Proano et al. (2012) & $x$ & & \\
\hline Rabta et al. (2018) & $x$ & $x$ & \\
\hline Rajgopal et al. (2011) & & & $x$ \\
\hline Rottkemper et al. (2011) & $x$ & & $x$ \\
\hline Shittu et al. (2016) & & $x$ & $x$ \\
\hline Yang et al. (2014) & $x$ & & $x$ \\
\hline HERMES: & & & \\
\hline Assi et al. (2011) & $x$ & $x$ & $x$ \\
\hline Assi et al. (2013) & $x$ & $x$ & $x$ \\
\hline Brown et al. (2014) & $x$ & $x$ & $x$ \\
\hline Haidari et al. (2013) & & $x$ & $x$ \\
\hline Haidari et al. (2015) & $x$ & $x$ & $x$ \\
\hline Haidari et al. (2016) & $x$ & & $x$ \\
\hline Lee et al. (2011a) & $x$ & $x$ & $x$ \\
\hline Lee et al. (2011b) & & $x$ & $x$ \\
\hline Lee et al. (2012a) & & $x$ & $\hat{x}$ \\
\hline Lee et al. (2012b) & & $x$ & $x$ \\
\hline Lee et al. (2015a) & $x$ & & $x$ \\
\hline Lee et al. (2016) & $x$ & & $x$ \\
\hline Lee et al. (2017) & $x$ & & $x$ \\
\hline Mueller et al. (2016) & $x$ & & $x$ \\
\hline Wedlock et al. (2019) & $x$ & $x$ & $x$ \\
\hline
\end{tabular}

Table 8: Classification according to performance measures.

Another insight demonstrated by Table 8 is that a majority of the articles simultaneously consider two types of performance measures. More specifically, approximately $54 \%$ of the selected manuscripts do so, while $30 \%$ solely measure one dimension and $16 \%$ report outcomes that capture all three dimensions. It should be noted that papers simultaneously accounting for all dimensions clearly represent a minority. Moreover, these are all HERMES papers. Indeed, Table 8 shows that in general, the HERMES papers tend to consult multiple dimensions in their analysis. That is, whereas only the HERMES papers combine the three types of performance measures, they also represent about half of the papers that look at two dimensions. Of course, it then follows that manuscripts not applying the HERMES simulation model seem to limit the number of dimensions they report outcomes on; these 
manuscripts represent approximately half of the articles that consider two dimensions and account for all of those that narrow down their focus to one dimension.

Examining the performance measures applied within each dimension, we find that nearly all papers considering the economic dimension look at costs. Additionally, Lee et al. (2017) report the incremental cost-effectiveness ratio (ICER). This is calculated as the difference in costs between a scenario and the baseline case, divided by the difference in disability-adjusted life years (DALYs). In their study, a scenario is considered cost-effective if it has an ICER smaller than three times the GDP per capita, and highly cost-effective if the ICER is below the GDP per capita. Only Proano et al. (2012) do not examine costs in their study. Rather, they look at total welfare, which they define as the sum of total profit and total customer surplus. Next, when observing the technological dimension, two performance measures often assessed are the storage and transportation capacity utilization (e.g., Lim et al., 2017; Shittu et al., 2016; HERMES papers). Other, more sporadically considered technological performance measures are the distance travelled (e.g., Hirsh Bar Gai et al., 2018; Rabta et al., 2018), travelling time (e.g., Rabta et al., 2018), and the packing efficiency (i.e., percentage of space occupied) (e.g., Norman et al., 2015). Last, the value dimension mostly concentrates on vaccine coverage (e.g., Chen et al., 2014; Dervaux et al., 2003; Lee et al., 2010; Lim et al., 2016; Mofrad et al., 2014; Mofrad et al., 2016; Mofrad et al., 2018; Norman et al., 2015; Rajgopal et al., 2011; Shittu et al., 2016; HERMES papers). Furthermore, this dimension also includes performance measures such as OVW (e.g., Assi et al., 2011; Azadi et al., 2019; Haidari et al., 2015; Mofrad et al., 2014; Mofrad et al., 2016; Mofrad et al., 2018; Yang et al., 2014), missed vaccination opportunities (e.g., Azadi et al., 2019; Mofrad et al., 2014; Mofrad et al., 2016; Mofrad et al., 2018; Mueller et al., 2016; Rottkemper et al., 2011), and vaccinepreventable infections and DALYs averted (e.g., Lee et al., 2017).

Discussion. In general, a majority of the selected OR/OM papers address multiple dimensions of performance measures in their analysis. However, they do not define how to prioritize between these performance indicators. In this regard, the use of multi-criteria decision methods can create added value in the field of VDCs in LMICs. Moreover, investigating the articles at a more detailed level, we note that mostly the HERMES papers tend to include multiple dimensions, whereas other manuscripts seem to limit their focus to one or two types of performance measures. We also observe that both the value and the economic dimensions are widely addressed, unlike the technological dimension. Although the value dimension is extremely important in a health or humanitarian setting, the technological dimension should not be overlooked as resources are often limited in VDCs in LMICs and hence should be utilized optimally.

\subsubsection{Real-life applicability}

Almost all the articles in our paper sample incorporate the first degree of real-life applicability (i.e., the use of real-life data as input into their analysis) (Table 9). Only Mofrad et al. (2014), Rabta et al. (2018) and Rajgopal et al. (2011) do not base their instances on actual data. Data sources used by the selected articles can be classified into four categories. First, many papers use data provided by health and humanitarian organizations including the WHO, GAVI, UNICEF, and PATH. Second, data can be obtained through national governments, in-country health officials, and local organizations. A third way of investigating realistic instances is the use of data as reported in other publications. Finally, some authors collect data themselves through interviews, field visits, and workshops.

On the contrary, manuscripts adopting the second and third degree of real-life applicability are scarce. Only five articles consult stakeholders during the course of their study. Chen et al. (2014) define scenarios based on communications with national health administrators. Lee et al. (2010) receive input from public health officials, and update and improve their models accordingly. Likewise, Brown et al. 
(2014) and Lee et al. (2016) work together with the national Ministries of Health. Finally, Assi et al. (2013) develop a simulation model in collaboration with the WHO and national partners. Note that all of these stakeholders fall into the categories of health and humanitarian organizations, and national governments. Hence, local stakeholders in the field such as patients and health care workers are not consulted during the studies carried out by our paper sample. Going one step further, the research done by Brown et al. (2014) and Lee et al. (2016) is implemented in practice. It should come as no surprise that both articles involved stakeholders during the course of their analysis.

\begin{tabular}{l|l}
\hline Real-life applicability & References \\
\hline Use of real-life data & Azadi et al. (2019); Chen et al. (2014); Chen et al. (2015); Dervaux et al. (2003); \\
& Dhamodharan et al. (2011); Dhamodharan and Proano (2012); Erdogan et al. (2017); Hirsh \\
& Bar Gai et al. (2018); Lee et al. (2010); Lim et al. (2016); Lim et al. (2017); Mofrad et al. \\
& (2016); Mofrad et al. (2018); Norman et al. (2013); Norman et al. (2015); Proano et al. \\
& (2012); Rottkemper et al. (2011); Shittu et al. (2016); Yang et al. (2014); \\
& HERMES [Assi et al. (2011); Assi et al. (2013); Brown et al. (2014); Haidari et al. (2013); \\
& Haidari et al. (2015); Haidari et al. (2016); Lee et al. (2011a); Lee et al. (2011b); Lee et al. \\
& (2012a); Lee et al. (2012b); Lee et al. (2015a); Lee et al. (2016); Lee et al. (2017); Mueller et \\
& al. (2016); Wedlock et al. (2019)]. \\
\hline Stakeholder involvement & Chen et al. (2014); Lee et al. (2010); \\
& HERMES [Assi et al. (2013); Brown et al. (2014); Lee et al. (2016)]. \\
\hline Implementation & HERMES [Brown et al. (2014); Lee et al. (2016)]. \\
\hline
\end{tabular}

Discussion. Almost all manuscripts use real-life data in their analysis. Regarding the issue of data availability and reliability, it is worth pointing out that models with approximate estimates, based on real-life data, can still provide valuable insights (i.e., perfect data will never be available and models need to do their best with what is available). However, research going beyond this point of real-life applicability is very limited. The observed small number of articles involving stakeholders in the analysis explains the even lower number of papers that is actually being implemented. As such, sitting together with stakeholders, exchanging ideas, and validating the developed models with them, might greatly improve the relevance of conducted academic research for practitioners in the field. This can eventually lead to more research being implemented. Moreover, this might be a start to close the gaps indicated by this literature review between the OR/OM literature on VDCs in LMICs and problems encountered in practice.

\subsubsection{Countries and vaccines covered}

Countries covered. Table 10 shows that a majority of the classified articles concentrate on the African continent. Moreover, within this continent, Niger, Benin, and Mozambique are studied most often. Addressed to a lesser extent, Asian countries looked at in our paper sample are Bangladesh, India, and Thailand. Alternatively, Proano et al. (2012) and Lee et al. (2015a) apply a different way to represent a real-life setting. Instead of focusing on predefined, specific countries, they classify all the relevant countries into different clusters. Next, based on the characteristics of each cluster, they create a hypothetical setting (e.g., Proano et al., 2012) or select a country they believe to be representative for the whole cluster (e.g., Lee et al., 2015a). Also, six articles do not include a case study in their analysis, but rather use a general, hypothetical setting. 


\begin{tabular}{|c|c|}
\hline Countries covered & References \\
\hline \multicolumn{2}{|l|}{ Asia } \\
\hline Bangladesh & $\begin{array}{l}\text { Azadi et al. (2019); Dervaux et al. (2003); Dhamodharan and Proano (2012); Yang et al. } \\
\text { (2014). }\end{array}$ \\
\hline India & Lim et al. (2016); Mofrad et al. (2018); Yang et al. (2014); \\
\hline Thailand & HERMES [Lee et al. (2017)]. \\
\hline \multicolumn{2}{|l|}{ Africa } \\
\hline Benin & Lim et al. (2017); Mofrad et al. (2016); Norman et al. (2015); \\
\hline & HERMES [Brown et al. (2014); Haidari et al. (2015); Lee et al. (2017)]. \\
\hline Botswana & Erdogan et al. (2017). \\
\hline Burundi & Rottkemper et al. (2011). \\
\hline Kenia & Mofrad et al. (2016). \\
\hline Lesotho & Erdogan et al. (2017). \\
\hline Mozambique & Mofrad et al. (2016); Yang et al. (2014); \\
\hline & HERMES [Haidari et al. (2016); Lee et al. (2016)]. \\
\hline Namibia & Erdogan et al. (2017). \\
\hline Niger & Chen et al. (2014); Chen et al. (2015); Lim et al. (2017); \\
\hline & $\begin{array}{l}\text { HERMES [Assi et al. (2011); Assi et al. (2013); Haidari et al. (2013); Lee et al. (2012a); Lee et } \\
\text { al. (2012b); Lee et al. (2017); Mueller et al. (2016)]. }\end{array}$ \\
\hline Nigeria & Hirsh Bar Gai et al. (2018); Shittu et al. (2016). \\
\hline South Africa & Erdogan et al. (2017). \\
\hline Swaziland & Erdogan et al. (2017). \\
\hline Uganda & Yang et al. (2014). \\
\hline Zambia & HERMES[Wedlock et al. (2019)]. \\
\hline All relevant countries & $\begin{array}{l}\text { Proano et al. (2012); } \\
\text { HERMES [Lee et al. (2015a)]. }\end{array}$ \\
\hline Not specified & $\begin{array}{l}\text { Dhamodharan et al. (2011); Lee et al. (2010); Mofrad et al. (2014); Norman et al. (2013); } \\
\text { Rabta et al. (2018); Rajgopal et al. (2011). }\end{array}$ \\
\hline
\end{tabular}

Table 10: Classification according to countries covered.

Vaccines covered. With respect to the vaccines considered in the analysis, we observe that a large number of papers model existing vaccines (Table 11). Most of these articles include multiple vaccines, often incorporating all the EPI vaccines administered in the country under study. Only a few manuscripts focus on one single vaccine; Azadi et al. (2019) look at the Pentavalent vaccine, Mofrad et al. (2016) and Mofrad et al. (2018) study the Measles vaccine, Rottkemper et al. (2011) consider the Meningitis vaccine, and Yang et al. (2014) focus on the Inactivated Polio vaccine.

Discussion. Classifying the relevant OR/OM papers according to countries and vaccines covered, we observe a few clear trends. First, articles tend to concentrate on the African continent, to a lesser extent on the Asian continent and, to the best of our knowledge, do not study the South-American continent. Moreover, within the African continent, research is particularly focused on a limited set of countries. This means that the topic of VDCs remains unexplored in many LMICs, providing opportunities for future research. Second, a clear majority of the papers model existing VDCs, thereby incorporating multiple existing vaccines. Studying different vaccines together is often necessary as, for example, they share limited storage and transportation capacity. 


\begin{tabular}{|c|c|}
\hline Vaccines covered & References \\
\hline \multicolumn{2}{|l|}{ Existing vaccines } \\
\hline One vaccine & $\begin{array}{l}\text { Azadi et al. (2019); Mofrad et al. (2016); Mofrad et al. (2018); Rottkemper et al. (2011); } \\
\text { Yang et al. (2014). }\end{array}$ \\
\hline Multiple vaccines & $\begin{array}{l}\text { Chen et al. (2014); Chen et al. (2015); Dervaux et al. (2003); Dhamodharan et al. (2011); } \\
\text { Dhamodharan and Proano (2012); Hirsh Bar Gai et al. (2018); Lee et al. (2010); Lim et al. } \\
\text { (2017); Norman et al. (2013); Norman et al. (2015); Proano et al. (2012); Shittu et al. (2016); } \\
\text { HERMES [Assi et al. (2011); Assi et al. (2013); Brown et al. (2014); Haidari et al. (2013); } \\
\text { Haidari et al. (2015); Haidari et al. (2016); Lee et al. (2011a); Lee et al. (2011b); Lee et al. } \\
\text { (2012a); Lee et al. (2012b); Lee et al. (2015a); Lee et al. (2016); Lee et al. (2017); Mueller et } \\
\text { al. (2016); Wedlock et al. (2019)]. }\end{array}$ \\
\hline Not specified & $\begin{array}{l}\text { Erdogan et al. (2017); Lim et al. (2016); Mofrad et al. (2014); Rabta et al. (2018); Rajgopal et } \\
\text { al. (2011). }\end{array}$ \\
\hline
\end{tabular}

Table 11: Classification according to vaccines covered.

\section{Conclusions and implications for future research}

In this paper, we review the literature on VDCs in LMICs, a very recent topic that is getting increased attention. The contribution of our literature review is three-fold. First, we give an overview of the main characteristics and challenges inherent to VDCs in LMICs. In order to do so, we include both quantitative and qualitative papers. Second, focusing on the OR/OM field, we provide an in-depth classification of the relevant OR/OM papers. The articles in our paper sample are categorized according to seven classification criteria: decision level, methodology, part of the VDC modelled, uncertainties and characteristics covered, performance measures, real-life applicability, and countries and vaccines covered. In this way, a detailed review is obtained where researchers can easily locate papers tailored to their interests. Third, this enables us to compare the issues reported in practice to those investigated in the OR/OM literature. Based on this analysis, we identify trends and conclude that several gaps exist, providing a promising avenue for future OR/OM research.

It becomes clear that the OR/OM literature mainly concentrates on the strategic decision level and to a lesser extent on the tactical and operational levels. Furthermore, our analysis reveals that most papers opt to use simulation. Articles applying this methodology often perform a scenario-based analysis. However, when the main goal of the research consists of finding an optimal solution, authors tend to favour the use of analytical methods over simulation. This means that simulation-optimization has not yet found its way to the field of VDCs in LMICs. Our literature review also indicates the wide range of performance measures being used in current OR/OM research; a majority of the selected OR/OM papers address multiple dimensions of performance measures in their analysis. However, it should be noted that it is mainly a specific group of papers (i.e., the HERMES papers) that tend to combine different types of performance measures. Surprisingly, even though many papers report on a variety of performance measures, they do not indicate how one should prioritize between them. In this regard, the use of multi-criteria decision making methods opens up interesting opportunities for further research.

A major finding of this literature review is that a variety of problems put forward in the broad literature on VDCs in LMICs receives little attention or even remains unexplored in the current OR/OM literature (e.g., allowing for horizontal shipments to make the VDC more flexible, outsourcing part of the VDC or integrating VDCs with other health care products, allocating health care staff). Also, we see that the number of modelled uncertainties and characteristics inherent to VDCs in LMICs is rather limited in the OR/OM community. It is then not surprising that our analysis reveals that real-life applicability is rather low. Although a laudable trend of including real-life data in the analysis is observed, we conclude that very few articles involve stakeholders in their study, resulting in an even lower number of papers being implemented in practice. Consequently, we believe that close collaboration between researchers and stakeholders, thereby including multiple types of stakeholders, is an important direction for future 
research. This has the potential to close the gaps identified throughout this literature review, while at the same time resulting in research tailored to practitioners' needs.

\section{Acknowledgements}

This work was supported by the GlaxoSmithKline Research Chair on Re-Design of Healthcare Supply Chains in Developing Countries to increase Access to Medicines.

\section{References}

Aina, M., Igbokwe, U., Jegede, L., Fagge, R., Thompson, A., \& Mahmoud, N. (2017). Preliminary results from direct-to-facility vaccine deliveries in Kano, Nigeria. Vaccine, 35(17), 2175-2183. https://doi.org/10.1016/j.vaccine.2016.11.100

Arya, J., \& Prausnitz, M. R. (2016). Microneedle patches for vaccination in developing countries. Journal of Controlled Release, 240, 135-141. https://doi.org/10.1016/j.jconrel.2015.11.019

Ashok, A., Brison, M., \& LeTallec, Y. (2017). Improving cold chain systems: Challenges and solutions. Vaccine, 35(17), 2217-2223. https://doi.org/10.1016/j.vaccine.2016.08.045

Assi, T.-M., Brown, S. T., Djibo, A., Norman, B. A., Rajgopal, J., Welling, J. S., et al. (2011). Impact of changing the measles vaccine vial size on Niger's vaccine supply chain: a computational model. $B M C$ Public Health, 11, 425. https://doi.org/10.1186/1471-2458-11-425

Assi, T.-M., Brown, S. T., Kone, S., Norman, B. A., Djibo, A., Connor, D. L., et al. (2013). Removing the regional level from the Niger vaccine supply chain. Vaccine, 31(26), 2828-2834. https://doi.org/10.1016/j.vaccine.2013.04.011

Azadi, Z., Gangammanavar, H., \& Eksioglu, S. (2019). Developing childhood vaccine administration and inventory replenishment policies that minimize open vial wastage. Annals of Operations Research. https://doi.org/10.1007/s10479-019-03164-8

Azimi, T., Franzel, L., \& Probst, N. (2017). Seizing market shaping opportunities for vaccine cold chain equipment. Vaccine, 35(17), 2260-2264. https://doi.org/10.1016/j.vaccine.2016.12.073

Brooks, A., Habimana, D., \& Huckerby, G. (2017). Making the leap into the next generation: A commentary on how Gavi, the Vaccine Alliance is supporting countries' supply chain transformations in 2016-2020. Vaccine, 35(17), 2110-2114. https://doi.org/10.1016/j.vaccine.2016.12.072

Brown, S. T., Schreiber, B., Cakouros, B. E., Wateska, A. R., Dicko, H. M., Connor, D. L., et al. (2014). The benefits of redesigning Benin's vaccine supply chain. Vaccine, 32(32), 4097-4103. https://doi.org/10.1016/j.vaccine.2014.04.090

Chen, S.-I., Norman, B. A., Rajgopal, J., Assi, T. M., Lee, B. Y., \& Brown, S. T. (2014). A planning model for the WHO-EPI vaccine distribution network in developing countries. IIE Transactions, 46(8), 853-865. https://doi.org/10.1080/0740817X.2013.813094

Chen, S.-I., Norman, B., Rajgopal, J., \& Lee, B. (2015). Passive cold devices for vaccine supply chains. Annals of Operations Research, 230(1), 87-104. https://doi.org/10.1007/s10479-013-1502-5

Comes, T., Bergtora Sandvik, K., \& Van de Walle, B. (2018). Cold chains, interrupted: The use of technology and information for decisions that keep humanitarian vaccines cool. Journal of Humanitarian Logistics and Supply Chain Management, 8(1), 49-69. https://doi.org/10.1108/JHLSCM03-2017-0006 
Decouttere, C., Vandaele, N., Lemmens, S., \& Bernuzzi, M. (2016). Advances in Managing Humanitarian Operations, chapter The vaccine supply chain multathlon: the reconciliation of technology, economy and access to medicines, 205-227. Springer International Series in Operations Research \& Management Science.

Dervaux, B., Leleu, H., Valdmanis, V., \& Walker, D. (2003). Parameters of control when facing stochastic demand: A DEA approach applied to Bangladeshi vaccination sites. International Journal of Health Care Finance and Economics, 3(4), 287-299. https://doi.org/10.1023/A:1026021407108

Dhamodharan, A., Proano, R., \& Kumar, S. (2011). A Stochastic Approach to Determine the Optimal Vaccine Vial Size. IIE Annual Conference Proceedings, 1-8. Retrieved from https://search.proquest.com/docview/1190390127?accountid=17215

Dhamodharan, A., \& Proano, R. A. (2012). Determining the optimal vaccine vial size in developing countries: a Monte Carlo simulation approach. Health Care Management Science, 15(3), 188-196. https://doi.org/10.1007/s10729-012-9200-4

Drain, P. K., Nelson, C. M., \& Llyod, J. S. (2003). Single-dose versus multi-dose vaccine vials for immunization programmes in developing countries. Bulletin of the World Health Organization, 81(10), 726-731. Retrieved from https://search.proquest.com/docview/71522446?accountid=17215

Duijzer, L. E., van Jaarsveld, W., \& Dekker, R. (2018). Literature review: The vaccine supply chain. European Journal of Operational Research, 268(1), 174-192. https://doi.org/10.1016/j.ejor.2018.01.015

Ebong, C., \& Levy, P. (2011). Impact of the introduction of new vaccines and vaccine wastage rate on the cost-effectiveness of routine EPI: lessons from a descriptive study in a Cameroonian health district. Cost Effectiveness and Resource Allocation, 9(1), 9. https://doi.org/10.1186/1478-7547-9-9

Erdogan, S, Kannan, S., \& Cheng, C. (2017). Optimization of vaccine delivery operations with regional distribution centers. IIE Annual Conference Proceedings, 1765-1770. Retrieved from https://search.proquest.com/docview/1951119986?accountid=17215

Gandhi, G., Lydon, P., Cornejo, S., Brenzel, L., Wrobel, S., \& Chang, H. (2013). Projections of costs, financing, and additional resource requirements for low- and lower middle-income country immunization programs over the decade, 2011-2020. Vaccine, 31, B137-B148. https://doi.org/10.1016/j.vaccine.2013.01.036

Gandhi, G., \& Lydon, P. (2014). Updating the evidence base on the operational costs of supplementary immunization activities for current and future accelerated disease control, elimination and eradication efforts. BMC Public Health, 14, 67. https://doi.org/10.1186/1471-2458-14-67

Guichard, S., Hymbaugh, K., Burkholder, B., Diorditsa, S., Navarro, C., Ahmed, S., et al. (2010). Vaccine wastage in Bangladesh. Vaccine, 28(3), 858-863. https://doi.org/10.1016/j.vaccine.2009.08.035

Guillermet, E., Dicko, H. M., Mai, L. T. P., N'diaye, M., Hane, F., Ba, S. O., et al. (2015). Acceptability and feasibility of delivering pentavalent vaccines in a compact, prefilled, autodisable device in Vietnam and Senegal. PLOS ONE, 10(7), e0132292. https://doi.org/10.1371/journal.pone.0132292

Guillermet, E., Alfa, D. A., Gbodja, R., \& Jaillard, P. (2017). Professional changes induced by a redesigned immunization supply chain in the Comé Health Zone, Benin. Vaccine, 35(17), 2189-2194. https://doi.org/10.1016/j.vaccine.2016.12.074 
Haidari, L. A., Connor, D. L., Wateska, A. R., Brown, S. T., Mueller, L. E., Norman, B. A., et al. (2013). Augmenting Transport versus Increasing Cold Storage to Improve Vaccine Supply Chains. PLOS ONE, 8(5), e64303. https://doi.org/10.1371/journal.pone.0064303

Haidari, L. A., Wahl, B., Brown, S. T., Privor-Dumm, L., Wallman-Stokes, C., Gorham, K., et al. (2015). One size does not fit all: The impact of primary vaccine container size on vaccine distribution and delivery. Vaccine, 33(28), 3242-3247. https://doi.org/10.1016/j.vaccine.2015.04.018

Haidari, L. A., Brown, S. T., Ferguson, M., Bancroft, E., Spiker, M., Wilcox, A., et al. (2016). The economic and operational value of using drones to transport vaccines. Vaccine, 34(34), 4062-4067. https://doi.org/10.1016/j.vaccine.2016.06.022

Heaton, A., Krudwig, K., Lorenson, T., Burgess, C., Cunningham, A., \& Steinglass, R. (2017). Doses per vaccine vial container: An understated and underestimated driver of performance that needs more evidence. Vaccine, 35(17), 2272-2278. https://doi.org/10.1016/j.vaccine.2016.11.066

Herlin, H., \& Pazirandeh, A. (2012). Nonprofit organizations shaping the market of supplies. International Journal of Production Economics, 139(2), 411-421. https://doi.org/10.1016/j.ijpe.2011.04.003

Hirsh Bar Gai, D., Graybill, Z., Voevodsky, P., \& Shittu, E. (2018). Evaluating scenarios of locations and capacities for vaccine storage in Nigeria. Vaccine, 36(24), 3505-3512. https://doi.org/10.1016/j.vaccine.2018.04.072

Hsiao, A., Desai, S. N., Mogasale, V., Excler, J.-L., \& Digilio, L. (2017). Lessons learnt from 12 oral cholera vaccine campaigns in resource-poor settings. Bulletin of the World Health Organization, 95(4), 303312. http://dx.doi.org/10.2471/BLT.16.175166

Huang, X. X., Guillermet, E., Le Gargasson, J.-B., Alfa, D. A., Gbodja, R., Sossou, A. J., et al. (2017). Costing analysis and anthropological assessment of the vaccine supply chain system redesign in the Comé District (Benin). Vaccine, 35(17), 2183-2188. https://doi.org/10.1016/j.vaccine.2016.12.075

Hutton, G., \& Tediosi, F. (2006). The costs of introducing a malaria vaccine through the expanded program on immunization in Tanzania. American Journal of Tropical Medicine and Hygiene, 75(Suppl 2), 119-130. https://doi.org/10.4269/ajtmh.2006.75.119

Karp, C. L., Lans, D., Esparza, J., Edson, E. B., Owen, K. E., Wilson, C. B., et al. (2015). Evaluating the value proposition for improving vaccine thermostability to increase vaccine impact in low and middleincome countries. Vaccine, 33(30), 3471-3479. https://doi.org/10.1016/j.vaccine.2015.05.071

Kaucley, L., \& Levy, P. (2015). Cost-effectiveness analysis of routine immunization and supplementary immunization activity for measles in a health district of Benin. Cost effectiveness and resource allocation, 13, 14. https://doi.org/10.1186/s12962-015-0039-7

Kaufmann, J. R., Miller, R., \& Cheyne, J. (2011). Vaccine supply chains need to be better funded and strengthened, or lives will be at risk. Health affairs, 30(6), 1113-1121. https://doi.org/10.1377/hlthaff.2011.0368

Kristensen, D. D., Lorenson, T., Bartholomew, K., \& Villadiego, S. (2016). Can thermostable vaccines help address cold-chain challenges? Results from stakeholder interviews in six low- and middle-income countries. Vaccine, 34(7), 899-904. https://doi.org/10.1016/j.vaccine.2016.01.001 
Lee, B. Y., Norman, B. A., Assi, T.-M., Chen, S.-I., Bailey, R. R., Rajgopal, J., et al. (2010). Single versus multi-dose vaccine vials: An economic computational model. Vaccine, 28(32), 5292-5300. https://doi.org/10.1016/j.vaccine.2010.05.048

Lee, B. Y., Assi, T.-M., Rookkapan, K., Connor, D. L. ; Rajgopal, J., Sornsrivichai, V., et al. (2011a). Replacing the measles ten-dose vaccine presentation with the single-dose presentation in Thailand. Vaccine, 29(21), 3811-3817. https://doi.org/10.1016/j.vaccine.2011.03.013

Lee, B. Y., Assi, T.-M., Rookkapan, K., Wateska, A. R., Rajgopal, J., Sornsrivichai, V., et al. (2011b). Maintaining Vaccine Delivery Following the Introduction of the Rotavirus and Pneumococcal Vaccines in Thailand. PLoS ONE, 6(9), e24673. https://doi.org/10.1371/journal.pone.0024673

Lee, B. Y., Assi, T.-M., Rajgopal, J., Norman, B. A., Chen, S.-I., Brown, S. T., et al. (2012a). Impact of introducing the pneumococcal and rotavirus vaccines into the routine immunization program in Niger. American Journal of Public Health, 102(2), 269-276. https://doi.org/10.2105/AJPH.2011.300218

Lee, B. Y., Cakouros, B. E., Assi, T.-M., Connor, D. L., Welling, J., Kone, S., et al. (2012b). The impact of making vaccines thermostable in Niger's vaccine supply chain. Vaccine, 30(38), 5637-5643. https://doi.org/10.1016/j.vaccine.2012.06.087

Lee, B. Y., Connor, D. L., Wateska, A. R., Norman, B. A., Rajgopal, J., Cakouros, B. E., et al. (2015a). Landscaping the structures of GAVI country vaccine supply chains and testing the effects of radical redesign. Vaccine, 33(36), 4451-4458. https://doi.org/10.1016/j.vaccine.2015.07.033

Lee, B. Y., Schreiber, B., Wateska, A. R., Connor, D. L., Dicko, H. M., Jaillard, P., et al. (2015b). The Benin experience: How computational modeling can assist major vaccine policy changes in low and middle income countries. Vaccine, 33(5), 2858-2861. https://doi.org/10.1016/j.vaccine.2015.04.022

Lee, B. Y., Haidari, L. A., Prosser, W., Connor, D. L., Bechtel, R., Dipuve, A., et al. (2016). Re-designing the Mozambique vaccine supply chain to improve access to vaccines. Vaccine, 34(41), 4998-5004. https://doi.org/10.1016/j.vaccine.2016.08.036

Lee, B. Y., \& Haidari, L. A. (2017). The importance of vaccine supply chains to everyone in the vaccine world. Vaccine, 35(35), 4475-4479. https://doi.org/10.1016/j.vaccine.2017.05.096

Lee, B. Y., Wedlock, P. T., Haidari, L. A., Elder, K., Potet, J., Manring, R., et al. (2017). Economic impact of thermostable vaccines. Vaccine, 35(23), 3135-3142. https://doi.org/10.1016/j.vaccine.2017.03.081

Lemmens, S., Decouttere, C., Vandaele, N., \& Bernuzzi, M. (2016). A review of integrated supply chain network design models: Key issues for vaccine supply chains. Chemical Engineering Research and Design, 109, 366-384. https://doi.org/10.1016/j.cherd.2016.02.015

Lennon, P., Atuhaire, B., Yavari, S., Sampath, V., Mvundura, M., Ramanathan, N., et al. (2017). Root cause analysis underscores the importance of understanding, addressing, and communicating cold chain equipment failures to improve equipment performance. Vaccine, 35(17), 2198-2202. https://doi.org/10.1016/j.vaccine.2016.09.068

Levin, A., Levin, C., Kristensen, D., \& Matthias, D. (2007). An economic evaluation of thermostable vaccines in Cambodia, Ghana and Bangladesh. Vaccine, 25(39), 6945-6957. https://doi.org/10.1016/j.vaccine.2007.06.065

Lewis, I., Ottosen, A., Rubin, J., Blanc, D. C., Zipursky, S., \& Wootton, E. (2017). A Supply and Demand Management Perspective on the Accelerated Global Introductions of Inactivated Poliovirus Vaccine in 
a Constrained Supply Market. Journal Of Infectious Diseases, 216(Suppl 1), S33-S39. https://doi.org/10.1093/infdis/jiw550

Lim, J., Claypool, E., Norman, B. A., \& Rajgopal, J. (2016). Coverage models to determine outreach vaccination center locations in low and middle income countries. Operations Research for Health Care, 9, 40-48. https://doi.org/10.1016/j.orhc.2016.02.003

Lim, J., Norman, B. A., \& Rajgopal, J. (2017). Process Redesign and Simplified Policies for More Effective Vaccine Inventory Management. Engineering Management Journal, 29(1), 17-25. https://doi.org/10.1080/10429247.2016.1277446

Lloyd, J., \& Cheyne, J. (2017). The origins of the vaccine cold chain and a glimpse of the future. Vaccine, 35(17), 2115-2120. https://doi.org/10.1016/j.vaccine.2016.11.097

Luzze, H., Badiane, O., Mamadou Ndiaye, E. H., Ndiaye, A. S., Atuhaire, B., Atuhebwe, P., et al. (2017). Understanding the policy environment for immunization supply chains: Lessons learned from landscape analyses in Uganda and Senegal. Vaccine, 35(17), 2141-2147. https://doi.org/10.1016/j.vaccine.2016.10.089

Lydon, P., Schreiber, B., Gasca, A., Dumolard, L., Urfer, D., \& Senouci, K. (2017). Vaccine stockouts around the world: Are essential vaccines always available when needed? Vaccine, 35(17), 2121-2126. https://doi.org/10.1016/j.vaccine.2016.12.071

Mccarney, S., Robertson, J., Arnaud, J., Lorenson, K., \& Lloyd, J. (2013). Using solar-powered refrigeration for vaccine storage where other sources of reliable electricity are inadequate or costly. Vaccine, 31(51), 6050-6057. https://doi.org/10.1016/j.vaccine.2013.07.076

Mofrad, M. H., Garcia, G.-G. P., Maillart, L. M., Norman, B. A., \& Rajgopal, J. (2016). Customizing immunization clinic operations to minimize open vial waste. Socio-Economic Planning Sciences, 54, 117. https://doi.org/10.1016/j.seps.2015.10.007

Mofrad, M. H., Maillart, L. M., Norman, B. A., \& Rajgopal, J. (2014). Dynamically optimizing the administration of vaccines from multi-dose vials. IIE Transactions, 46(7), 623-635. https://doi.org/10.1080/0740817X.2013.849834

Mofrad, M., Maillart, L. M., Norman, B. A., \& Rajgopal, J. (2018). Multi-dose vial administration with non-stationary demand and delayed service. Operations Research for Health Care, 19, 66-79. https://doi.org/10.1016/j.orhc.2018.03.003

Molemodile, S., Wotogbe, M., \& Abimbola, S. (2017). Evaluation of a pilot intervention to redesign the decentralised vaccine supply chain system in Nigeria. Global Public Health, 12(5), 601-616. https://doi.org/10.1080/17441692.2017.1291700

Mueller, L. E., Haidari, L. A., Wateska, A. R., Phillips, R. J., Schmitz, M. M., Connor, D. L., et al. (2016). The impact of implementing a demand forecasting system into a low-income country's supply chain. Vaccine, 34(32), 3663-3669. https://doi.org/10.1016/j.vaccine.2016.05.027

Mvundura, M., Lorenson, K., Chweya, A., Kigadye, R., Bartholomew, K., Makame, M., et al. (2015). Estimating the costs of the vaccine supply chain and service delivery for selected districts in Kenya and Tanzania. Vaccine, 33(23), 2697-2703. https://doi.org/10.1016/j.vaccine.2015.03.084

Norman, B. A., Nourollahi, S., Chen, S.-I., Brown, S. T., Claypool, E. G., Connor, D. L., et al. (2013). A passive cold storage device economic model to evaluate selected immunization location scenarios. Vaccine, 31(45), 5232-5238. https://doi.org/10.1016/j.vaccine.2013.08.079 
Norman, B. A., Rajgopal, J., Lim, J., Gorham, K., Haidari, L., Brown, S. T., et al. (2015). Modular vaccine packaging increases packing efficiency. Vaccine, 33(27), 3135-3141. https://doi.org/10.1016/j.vaccine.2015.04.091

Ottih, C., Cussen, K., \& Mustafa, M. (2018). Building Strong Health Supply Chain Systems: The Visibility and Analytics Network approach to improving the Nigeria Immunization Supply Chain. Journal of innovation in health informatics, 25(4), 199-206. http://dx.doi.org/10.14236/jhi.v25i4.944

Parmar, D., Baruwa, E. M., Zuber, P., \& Kone, S. (2010). Impact of wastage on single and multi-dose vaccine vials: Implications for introducing pneumococcal vaccines in developing countries. Human Vaccines, 6(3), 270-278. https://doi.org/10.4161/hv.6.3.10397

Pazirandeh, A. (2011). Sourcing in global health supply chains for developing countries: Literature review and a decision making framework. International Journal of Physical Distribution \& Logistics Management, 41(4), 364-384. https://doi.org/10.1108/09600031111131931

Proano, R. A., Jacobson, S. H., \& Zhang, W. (2012). Making combination vaccines more accessible to low-income countries: The antigen bundle pricing problem. Omega, 40(1), 53-64. https://doi.org/10.1016/j.omega.2011.03.006

Prosser, W., Jaillard, P., Assy, E., Brown, S. T., Matsinhe, G., Dekoun, M., et al. (2017). System redesign of the immunization supply chain: Experiences from Benin and Mozambique. Vaccine, 35(17), 21622166. https://doi.org/10.1016/j.vaccine.2016.09.073

Rabta, B., Wankmüller, C., \& Reiner, G. (2018). A drone fleet model for last-mile distribution in disaster relief operations. International Journal of Disaster Risk Reduction, 28, 107-112. https://doi.org/10.1016/j.ijdrr.2018.02.020

Rajgopal, J., Connor, D. L., Assi, T.-M., Norman, B. A., Chen, S.-I., Bailey, R. R., et al. (2011). The optimal number of routine vaccines to order at health clinics in low or middle income countries. Vaccine, 29(33), 5512-5518. https://doi.org/10.1016/j.vaccine.2011.05.044

Riewpaiboon, A., Sooksriwong, C., Chaiyakunapruk, N., Tharmaphornpilas, P., Techathawat, S., Rookkapan, K., et al. (2015). Optimizing national immunization program supply chain management in Thailand: an economic analysis. Public Health, 129(7), 899-906. https://doi.org/10.1016/j.puhe.2015.04.016

Rottkemper, B., Fischer, K., Blecken, A., \& Danne, C. (2011). Inventory relocation for overlapping disaster settings in humanitarian operations. OR Spectrum, 33(3), 721-749. https://doi.org/10.1007/s00291-011-0260-5

Sarley, D., Mahmud, M., Idris, J., Osunkiyesi, M., Dibosa-Osadolor, O., Okebukola, P., et al. (2017). Transforming vaccines supply chains in Nigeria. Vaccine, 35(17), 2167-2174. https://doi.org/10.1016/j.vaccine.2016.11.068

Schmidt, G., \& Wilhelm, W.E. (2000). Strategic, tactical and operational decisions in multi-national logistics networks: A review and discussion of modelling issues. International Journal of Production Research, 38(7), 1501-1523. https://doi.org/10.1080/002075400188690

Shittu, E., Harnly, M., Whitaker, S., \& Miller, R. (2016). Reorganizing Nigeria's vaccine supply chain reduces need for additional storage facilities, but more storage is required. Health affairs, 35(2), 293300. https://doi.org/10.1377/hlthaff.2015.1328 
Songane, M. (2018). Challenges for nationwide vaccine delivery in African countries. International Journal of Health Economics and Management, 18(2), 197-219. https://doi.org/10.1007/s10754-0179229-5

Vandaele, N.J., \& Decouttere, C.J. (2013). Sustainable R\&D portfolio assessment. Decision Support Systems, 54(4), 1521-1532. https://doi.org/10.1016/j.dss.2012.05.054

van den Ent, M. M. V. X., Yameogo, A., Ribaira, E., Hanson, C. M., Ratoto, R., Rasolomanana, S., et al. (2017). Equity and immunization supply chain in Madagascar. Vaccine, 35(17), 2148-2154. https://doi.org/10.1016/j.vaccine.2016.11.099

Wallace, A., Dietz, V., \& Cairns, K. L. (2009). Integration of immunization services with other health interventions in the developing world: what works and why? Systematic literature review. Tropical Medicine and International Health, 14(1), 11-19. https://doi.org/10.1111/j.1365-3156.2008.02196.x

Wallace, A. S., Willis, F., Nwaze, E., Dieng, B., Sipilanyambe, N., Daniels, D., et al. (2017). Vaccine wastage in Nigeria: An assessment of wastage rates and related vaccinator knowledge, attitudes and practices. Vaccine, 35(48), 6751-6758. https://doi.org/10.1016/j.vaccine.2017.09.082

Wedlock, P. T., Mitgang, E. A., Haidari, L. A., Prosser, W., Brown, S. T., Krudwig, K., et al. (2019). The value of tailoring vial sizes to populations and locations. Vaccine, 37(4), 637-644. https://doi.org/10.1016/j.vaccine.2018.12.010

WHO. (2017, July). Immunization coverage: fact sheet. Retrieved from http://www.who.int/mediacentre/factsheets/fs378/en/

WHO/UNICEF. (2017a, July). Progress and challenges with achieving universal immunization coverage: 2016 estimates of immunization coverage. Retrieved from http://www.who.int/immunization/monitoring_surveillance/who-immuniz.pdf?ua=1

WHO/UNICEF. (2017b, July). Progress towards global immunization goals - 2016: summary presentation of key indicators. Retrieved from http://apps.who.int/gho/cabinet/gvap.jsp

Woodle, D. (2000). Vaccine procurement and self-sufficiency in developing countries. Health Policy and Planning, 15(2), 121-129. https://doi.org/10.1093/heapol/15.2.121

Yadav, P. (2015). Health Product Supply Chains in Developing Countries: Diagnosis of the Root Causes of Underperformance and an Agenda for Reform. Health Systems \& Reform, 1(2), 142-154. https://doi.org/10.4161/23288604.2014.968005

Yadav, P., Lydon, P., Oswald, J., Dicko, M., \& Zaffran, M. (2014). Integration of vaccine supply chains with other health commodity supply chains: a framework for decision making. Vaccine, 32(50), 67256732. https://doi.org/10.1016/j.vaccine.2014.10.001

Yang, W., Parisi, M., Lahue, B. J., Uddin, Md. J., \& Bishai, D. (2014). The budget impact of controlling wastage with smaller vials: A data driven model of session sizes in Bangladesh, India (Uttar Pradesh), Mozambique, $\quad$ and $\quad$ Uganda. 32(49), 6643-6648. https://doi.org/10.1016/j.vaccine.2014.09.057

Zaffran, M., Vandelaer, J., Kristensen, D., Melgaard, B., Yadav, P., Antwi-Agyei, K. O., et al. (2013). The imperative for stronger vaccine supply and logistics systems. Vaccine, 31(2), B73-B80. https://doi.org/10.1016/j.vaccine.2012.11.036 
Zipursky, S., Djingarey, M. H., Lodjo, J.-C., Olodo, L., Tiendrebeogo, S., \& Ronveaux, O. (2014). Benefits of using vaccines out of the cold chain: Delivering Meningitis A vaccine in a controlled temperature chain during the mass immunization campaign in Benin. Vaccine, 32(13), 1431-1435. https://doi.org/10.1016/j.vaccine.2014.01.038 